\title{
Intense highly charged ion beam production and operation with a superconducting electron cyclotron resonance ion source
}

\author{
H. W. Zhao, ${ }^{1,}{ }^{*}$ L. T. Sun, ${ }^{1}$ J. W. Guo, ${ }^{1}$ W. Lu, ${ }^{1}$ D. Z. Xie, ${ }^{2}$ D. Hitz, ${ }^{1, \dagger}$ X. Z. Zhang, ${ }^{1}$ and Y. Yang ${ }^{1}$ \\ ${ }^{1}$ Institute of Modern Physics, Chinese Academy of Sciences, Lanzhou 730000, China \\ ${ }^{2}$ Nuclear Science Division, Lawrence Berkeley National Laboratory, Berkeley, California 94720, USA
}

(Received 11 January 2017; published 21 September 2017)

\begin{abstract}
The superconducting electron cyclotron resonance ion source with advanced design in Lanzhou (SECRAL) is a superconducting-magnet-based electron cyclotron resonance ion source (ECRIS) for the production of intense highly charged heavy ion beams. It is one of the best performing ECRISs worldwide and the first superconducting ECRIS built with an innovative magnet to generate a high strength minimumB field for operation with heating microwaves up to 24-28 GHz. Since its commissioning in 2005, SECRAL has so far produced a good number of continuous wave intensity records of highly charged ion beams, in which recently the beam intensities of ${ }^{40} \mathrm{Ar}^{12+}$ and ${ }^{129} \mathrm{Xe}^{26+}$ have, for the first time, exceeded 1 emA produced by an ion source. Routine operations commenced in 2007 with the Heavy Ion accelerator Research Facility in Lanzhou (HIRFL), China. Up to June 2017, SECRAL has been providing more than 28,000 hours of highly charged heavy ion beams to the accelerator demonstrating its great capability and reliability. The great achievement of SECRAL is accumulation of numerous technical advancements, such as an innovative magnetic system and an efficient double-frequency $(24+18 \mathrm{GHz})$ heating with improved plasma stability. This article reviews the development of SECRAL and production of intense highly charged ion beams by SECRAL focusing on its unique magnet design, source commissioning, performance studies and enhancements, beam quality and long-term operation. SECRAL development and its performance studies representatively reflect the achievements and status of the present ECR ion source, as well as the ECRIS impacts on HIRFL.
\end{abstract}

DOI: 10.1103/PhysRevAccelBeams.20.094801

\section{INTRODUCTION}

ECRIS (electron cyclotron resonance ion source) is a plasma device dedicated to the production of intense singly and highly charged ion beams [1]. Highly charged ion beams enable the accelerators to produce very energetic ions at substantially lower cost and much smaller machine footprints, as the energy gains from heavy ion accelerators are either proportional to the ion charge state $Q$ or $Q^{2}$. Since its advent, ECRIS has been playing a significant role in enhancing the capabilities of many cyclotrons, linacs, and synchrotrons with much greater variety of ion species, beam intensity and ion energy, and operation reliability [1-3]. The enhancements of accelerators from ECRIS have led to substantially greater research opportunities in nuclear physics, atomic physics, and other disciplines, as well as various industrial applications. It may be arguable to say

\footnotetext{
*Corresponding author. zhaohw@impcas.ac.cn

${ }^{\dagger}$ Retired from CEA/Grenoble, France. A visiting scientist at IMP.

Published by the American Physical Society under the terms of the Creative Commons Attribution 4.0 International license. Further distribution of this work must maintain attribution to the author(s) and the published article's title, journal citation, and DOI.
}

that without ECRIS it would be very difficult or unlikely to continue the syntheses of new superheavy elements or to construct a national facility of radioactive ion beams to further nuclear physics research, while heavy ion cancer therapy would likely remain a dream [1-3].

Since SUPERMAFIOS $[1,4]$, the first of the first generation high charge state ECR ion source developed in Grenoble in the mid-1970s, the ECRIS performance on the ion charge state and beam intensity has been leaping forward greatly with each new generation source developed. The category of the "generation" in ECRIS is based on the operating frequency: first generation at $5-10 \mathrm{GHz}$; second generation at $14-18 \mathrm{GHz}$; third generation at 20-28 GHz and fourth generation at $>28 \mathrm{GHz}$. To date, there are three "generations" of ECRIS developed and demands by heavy ion accelerators for more intense and higher charge state heavy ion beams have been driving the ongoing development of the fourth generation [3]. Many of the existing, under-construction and next generation accelerators require very intense highly charged heavy ion beams. One can cite, for instance, 1 emA of pulsed ${ }^{208} \mathrm{~Pb}^{27+}$ for CERN LHC [5], 1 emA of pulsed ${ }^{238} \mathrm{U}^{28+}$ for the FAIR project [6], $0.4 \mathrm{emA}$ of continuous wave (cw) mixed beam of ${ }^{238} \mathrm{U}^{33+}$ and ${ }^{238} \mathrm{U}^{34+}$ for the FRIB project [7], $1 \mathrm{emA}$ of cw ${ }^{36} \mathrm{Ar}^{12+}$ for GANIL SPIRAL2 [8], $0.5 \mathrm{emA}$ of $\mathrm{cw}$ ${ }^{238} \mathrm{U}^{35+}$ for RIKEN RIBF [9], $0.85 \mathrm{emA}$ of $\mathrm{cw}{ }^{238} \mathrm{U}^{35+}$ and 
1.7 emA of pulsed ${ }^{238} \mathrm{U}^{35+}$ for the IMP HIAF project [10]. Successful accelerations of these intense highly charged ion beams directly provided by an ion source will result in a relatively low cost accelerator, and definitely would lead to much higher beam power providing many new opportunities in physics research. However none of the existing ion sources could produce all of the required ion beam intensities, but ECRIS has the greatest potential to meet these requirements. Based on the demonstrated performance of the third generation ECRISs, a fourth generation ECRIS operating at higher heating microwave frequency and then at higher magnetic fields will be able to meet all of the aforementioned demands.

Developments have demonstrated that ECRIS operating at higher magnetic fields and higher heating microwave frequency is the most straightforward path to achieve higher source performance. Nonetheless, high magnetic fields would need to use superconducting magnets and one must cite the early pioneering developments of superconducting ECRISs which, however, were operated at rather low fields and frequencies. These trailblazers include ECREVIS [11-13], the first superconducting-magnetbased ECRIS developed in 1983 in Louvain-La-Neuve, Belgium; Jülich ICIS [14], commissioned in 1988 in Wilhelm-Johnen, Germany; MSU SCECR [15], a 6.4 GHz ECRIS commissioned in 1989 in East Lansing, USA, and INFN SERSE [16-17], developed in the early 1990s in Grenoble and Catania. These pioneers have addressed some of the challenges in building complex superconducting magnets for higher-field ECRISs, from which today's highest magnetic fields for the third generation of ECRIS are $4 \mathrm{~T}$ for the axial field, and $2.2 \mathrm{~T}$ for the radial field at the inner surface of the plasma chamber.

VENUS, a fully superconducting ECRIS built at LBNL and operating at $18-28 \mathrm{GHz}$, one of the best performing of the third generation ECRIS, had been commissioned successfully in the early 2000s [13,18-19]. Then, SECRAL, from IMP-Lanzhou operating at $18-24 \mathrm{GHz}$, was commissioned in 2005. This is the fully superconducting ECR source with the smallest footprint, thanks to its novel magnet structure. Following SECRAL came several more third generation performing ECRISs, such as SuSI at NSCL/MSU [20-21], RIKEN-SCECR [22], and KBSISCECR [23]. These third generation ECRISs have not only successfully enhanced by a factor 2-10 the ion beam current, but also delivered new high ion charge states.

However, the developments of the third generation ECRISs have continuously encountered technical challenges, such as the difficulties in fabricating a higher-field superconducting magnet system because of the very strong Lorentz force that is proportional to the square of the magnetic field strength $B$ and the complex force patterns. Other issues encountered by the designers of these machines are high power microwave coupling, plasma chamber cooling, strong bremsstrahlung radiations from plasma leading to the magnet cryostat heat load increase and to a fragility of the plasma chamber high voltage, extraction and transport of intense multiply charged ion beam.

The development of SECRAL is to provide intense highly charged ion beams to enhance the capability of the Heavy Ion Research Facility in Lanzhou-China (HIRFL), an accelerator complex based on heavy ion cyclotrons and cooling storage rings [24-26]. The commissioning of SECRAL took place in 2005 [27-28], and since 2007 this third generation ECRIS has been in routine operation for HIRFL [29-30]. Performance of the SECRAL source has been continuously improved in terms of beam intensity, charge states and beam stability, especially during the past years thanks to the use of new techniques or "tricks" [31-35]. Beam intensities of the highly charged heavy ions have been increased by a factor of 3-10, setting then many beam records produced by an ECRIS in cw mode. So far, SECRAL has strongly shifted the fateful $1 \mathrm{emA}$ level given by an ECRIS as it delivers more than $1.4 \mathrm{emA}$ of ${ }^{40} \mathrm{Ar}^{12+}$ and $1.1 \mathrm{emA}$ of ${ }^{129} \mathrm{Xe}^{26+}$ [35]. Regarding high charge states, SECRAL can deliver $0.32 \mathrm{emA}$ of ${ }^{129} \mathrm{Xe}^{30+}, 0.68 \mathrm{emA}$ of ${ }^{209} \mathrm{Bi}^{31+}$ and $10 \mathrm{e} \mu \mathrm{A}$ of ${ }^{209} \mathrm{Bi}^{50+}$. This outstanding SECRAL performance has significantly contributed to HIRFL capability enhancement in ion beam energy, intensity and variety. For example, thanks to the highly charged ion beams exiting from SECRAL and HIRFL, such as ${ }^{40} \mathrm{Ca}^{11+},{ }^{58} \mathrm{Ni}^{19+},{ }^{112} \mathrm{Sn}^{26+}$, ${ }^{209} \mathrm{Bi}^{31+}$ and ${ }^{238} \mathrm{U}^{32+}$, nuclear physicists have synthesized, at IMP, many new isotopes and conducted high precision mass measurements of 35 short-lived nuclides for the first time [36]. To date the total beam delivery to HIRFL by SECRAL has reached more than 28,000 hours, a good demonstration of the SECRAL reliability and a record for a third generation ECRIS in operation with an accelerator.

The success of SECRAL and the achievements of other superconducting ECRISs, such as LNS SERSE [17], LBNL VENUS [13], RIKEN SCECR [22] and MSU SuSI [21], have embodied the third generation ECR ion sources in advancing the ECRIS technology. After a brief reminder of ECRIS principles, this article reviews the development of SECRAL mostly in terms of magnetic structure design and microwave coupling.

\section{ECRIS GENERAL PRINCIPLE}

ECRIS is a microwave-driven plasma device originated from fusion research [4]. Although it has been developing for more than four decades, the detailed physics processes involved in the ECR hot plasma remain poorly understood, due to the difficulties in decoupling the parameters. The detailed physics processes include the plasma magnetic confinement, ionization and atomic properties, interaction between electromagnetic waves and plasma (plasma heating), interaction between plasma and chamber surface of different materials, microwave coupling and multimode 
resonator, beam formation, etc. There have been many studies on the ECRIS physics [37-55], especially in the recent years, resulting in a number of plausible and essential conclusions.

Generally speaking, ECR plasma is produced and energized by microwave power through electron cyclotron resonance heating, in which the electrons oscillate along the magnetic mirror lines in a minimum-B configuration absorbing the microwave energy when the electron gyrofrequency equals the incoming microwave frequency:

$$
\omega_{e}=\frac{e \cdot B_{\mathrm{ECR}}}{m}=\omega_{r f},
$$

where $m$ is the mass and $e$ the electric charge of the electron, $B_{\mathrm{ECR}}$ is the resonant magnetic field, $\omega_{e}$ and $\omega_{r f}$ are the electron gyrofrequency and the microwave frequency, respectively. The resulted energetic electrons ionize the atoms and lowly charged ions through sequential impact ionization so that the ions could reach as high charge state as possible provided a long ion lifetime. The ECR plasma is confined and stabilized by a "minimum-B" magnetic field produced by mirror coils superimposed with a radial field mostly generated by a sextupole magnet, as schematically shown in Fig. 1. In ECRIS plasma, the key parameters, determining the highly charged ion yield, are the electron density $n_{e}$, the ion confinement time $\tau_{i}$, the electron temperature $T_{e}$ and the neutral density $n_{0}$. To achieve high throughput of highly charged ions, the product of $n_{e} \tau_{i}$ should be as high as possible so that there is a high enough number of electrons carrying out the ionizations and the ions can stay a long enough time to reach the desired charge state. The electron density $n_{e}$ is related to the microwave frequency, the absorbed microwave power, the magnetic field and the neutral density in the plasma [40,56]. The loss of high charge state ions is determined by plasma ambipolar diffusion, charge exchange among the neutrals and low charge state ions. Therefore, low neutral pressure is preferable and needed inside the plasma to maximize the yields of the highly charged ions.

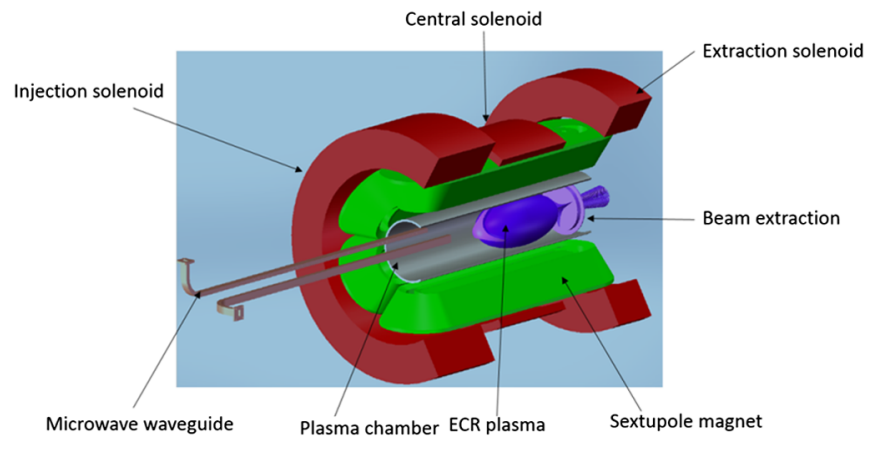

FIG. 1. Schematic view of the ECR ion source structure with minimum-B magnet configuration.
The highly charged ions are produced by stepwise electron-impact ionization in ECR plasma, and therefore the ions have to stay a quite long time in the plasma to reach the high charge states. In ECRIS the ions are relatively cold, having energy in the range of a few $q \mathrm{eV}$ ( $q$ being the ion charge), highly collisional and not magnetized.

The extracted ion current from an ECR ion source corresponds to the losses of the plasma confinement and can be written as $[2,57]$

$$
I_{i}=\left(n_{i} q e V / \tau_{i}\right) \eta_{p}
$$

where $I_{i}$ is the extracted ion beam current, $q$ is the ion charge state, $V$ is the plasma volume and $\eta_{p}$ is the efficiency of the plasma flow from the main plasma to the extraction hole of the ECR ion source.

The performance of a highly charged ECR ion source strongly depends on optimization of the ECR plasma and then a good understanding of the physics processes is crucial. Since the advent of ECRIS, the knowledge of its plasma behavior is mostly semiempirical, with nevertheless several theoretical models. In 1987, Geller had suggested a few ECRIS scaling laws pointing out that the electron density and the intensity of highly charged ions are proportional to the square of the microwave frequency, while the ion confinement time is related to the magnetic mirror ratio [58-59]. The so-called high-B mode with higher magnetic fields for highly charged ECR ion source was proposed by Gammino [56,60-61]. Ten years later, a set of new empirical criteria for designing an ECRIS magnetic field configuration has been established based on experimental results from the SERSE superconducting ECR source [62]. Recently some scaling laws were proposed to illustrate the role of the microwave power as well as the axial minimum-magnetic-field $B_{\min }$ based upon experimental results from the LBL VENUS ECR ion source [63-65].

Based upon the basic ECR physics, scaling laws and the history of ECRIS development, it comes out that, to produce intense highly charged ion beams, one must use high microwave heating frequency to push the cutoff frequency to high values. This requires then strong magnetic fields and leads to high microwave power. As a consequence, for ECR ion sources operating at microwave frequency above $18 \mathrm{GHz}$, the magnetic bottle has to be made of superconducting magnets. Numerous technical challenges have been addressed and overcome during the development of the NbTi-magnet-based superconducting ECR ion sources, such as the LNS SERSE [17], LBNL VENUS [13], IMP SECRAL [31], MSU SuSI [21], RIKEN SCECR [22] and other third generation ECRISs under development $[23,66]$. However, there are still many new technical challenges to be addressed for the construction of a future source based on $\mathrm{Nb}_{3} \mathrm{Sn}$ magnet systems [67]. 


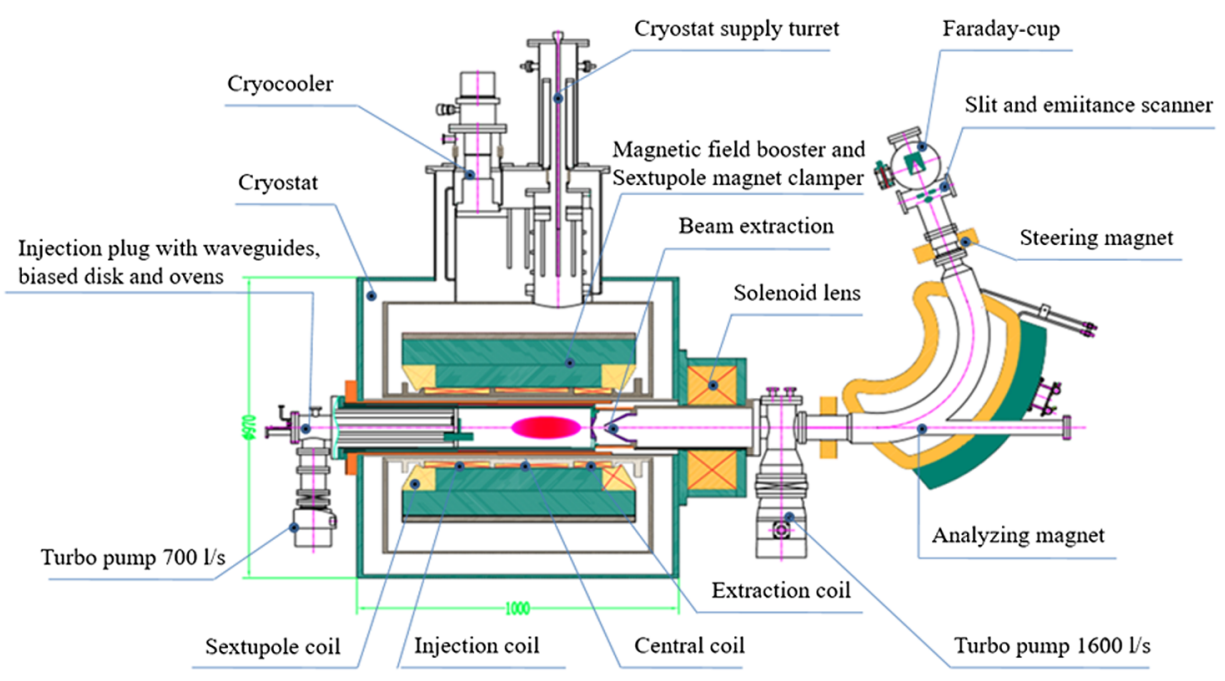

FIG. 2. Layout of the SECRAL ion source and its beam transport line.

\section{THE DEVELOPMENT OF SECRAL}

\section{A. SECRAL overview}

SECRAL is a third generation fully superconducting $24 \mathrm{GHz}$ ECR ion source, with magnetic field maxima of 3.6 T on axis and $2.0 \mathrm{~T}$ radially at the plasma chamber inner wall. The goal of SECRAL is to enhance the production of highly charged heavy ion beams with reliable long-term stability needed for the HIRFL accelerator.

Figure 2 schematically shows the key footprints of SECRAL with its ion beam analysis and diagnostics.
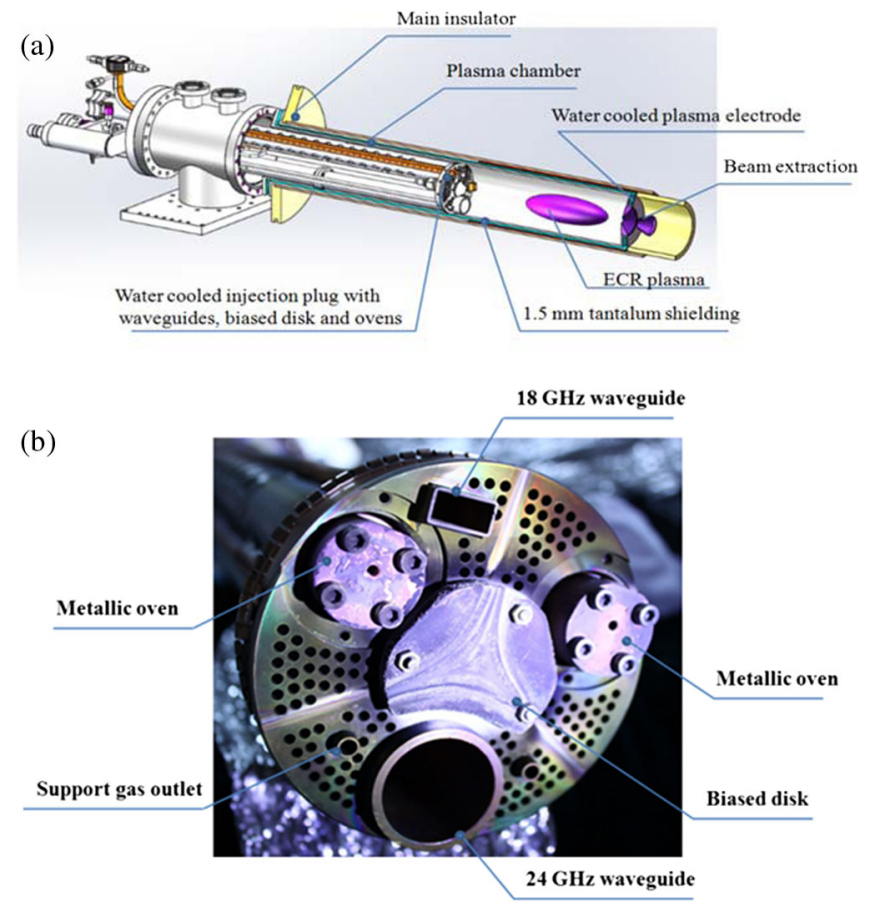

FIG. 3. Conventional components of the SECRAL source: (a) schematic view of the injection tank; (b) photo of the injection tank end.
SECRAL comprises an innovative compact superconducting magnet surrounding a plasma chamber with dimensions close to LNS-SERSE (ID = 120-126 mm), an injection system dedicated to microwave, gas and metals feeds and a beam extraction mechanism, as shown in Figs. 3 and 4. The double-wall plasma chamber is made of either stainless steel or aluminum with water cooling channels in between. In addition, the cooling water runs through the whole chamber up to the location of the extraction electrode to provide sufficient thermal conduction cooling. A $1.5 \mathrm{~mm}$ thick tantalum liner encloses the plasma chamber to strongly reduce the hard $\mathrm{x}$-ray damage to the high voltage PEEK insulator and thermal load to the magnet cryostat [68]. A $700 \mathrm{l} / \mathrm{s}$ and a $1600 \mathrm{l} / \mathrm{s}$ turbomolecular pump is installed at the injection and the extraction region respectively to achieve the high vacuum needed for the production of highly charged ions. Ions are extracted at voltages ranging from 20 to $30 \mathrm{kV}$ to match the accelerator requirement and minimize ion beam transport losses.

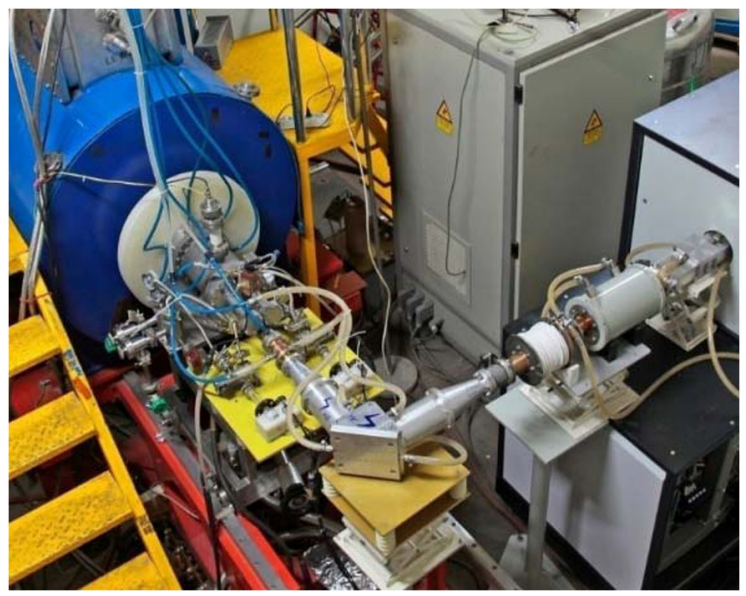

FIG. 4. The SECRAL source with $24 \mathrm{GHz}$ microwave coupling. 


\section{B. Novel superconducting magnet and magnetic field distribution}

Typically, the magnetic structure of an ECRIS is made of axial solenoid coils surrounding the radial sextupole magnets (called Sext-in-Sol), whatever the materials, room temperature or superconducting wires. Such classical magnetic structure is shown in Fig. 5(a). The novel feature of the SECRAL superconducting magnet is to locate the axial solenoid coils inside the radial sextupole magnet (called Sol-In-Sext), as shown in Fig. 5(b).

Regarding the Sext-in-Sol structure, the sextupole is surrounded three or more solenoids to get the magnetic mirror profile. The sextupole is made of six curved racetrack coils to generate a radial field proportional to the square of its radius. In such a classical magnet structure, the complex and very strong Lorentz interaction forces result in very challenging coil clamping, especially if the racetrack coil ends are close to the solenoids. At each side of the magnetic structure, i.e. injection and extraction, there are six sextupole ends in which the current flows oppositely to the adjacent end, as shown in Fig. 6. This alternating current interacts with the magnetic field produced by the solenoids resulting in forces outward and inward radially, and axially that push and pull the sextupole ends. As counteractions, there are strong axial repulsions and attractions on the solenoid coils. In addition there are

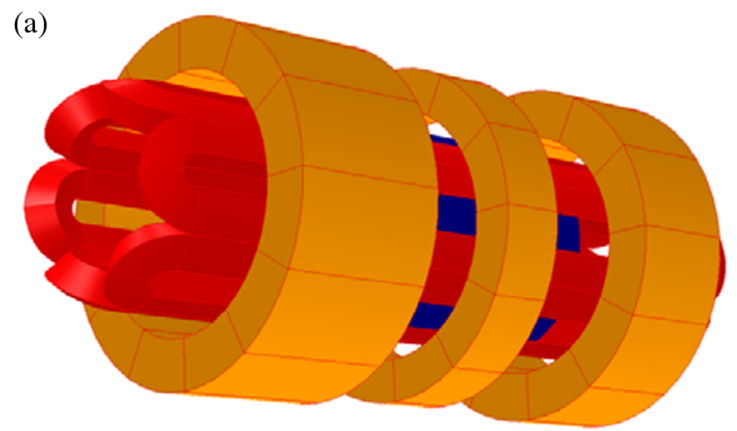

(b)

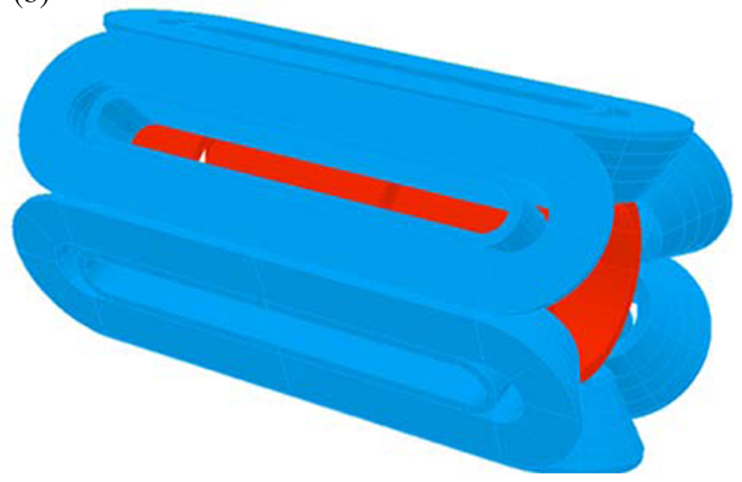

FIG. 5. Magnet coil configuration of the highly charged ECRIS. Classical ECRIS magnet coil configuration of Sext-InSol. The SECRAL superconducting magnet coil configuration of Sol-In-Sext.

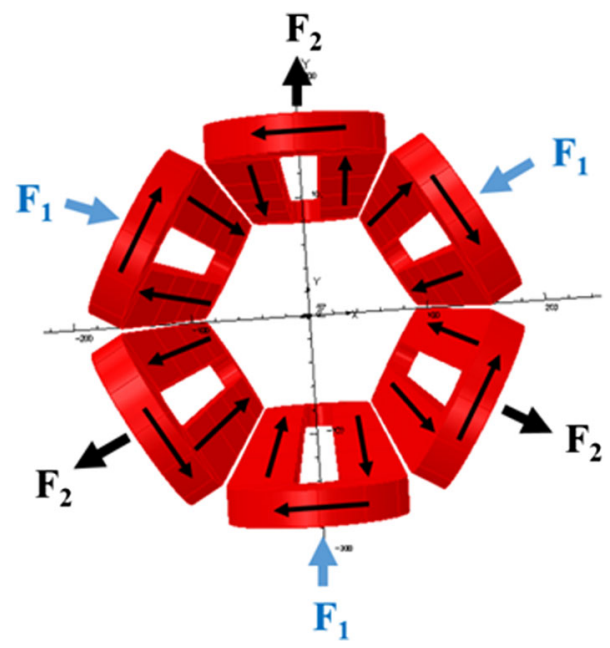

FIG. 6. View of sextupole-coil end in which the adjacent end electric-current flows oppositely. Interaction between the end currents and the axial fields results in strong radially inward force F1 and outward force F2.

strong azimuthally positive/negative forces on the straight sections of the sextupole coils as well, due to the interaction with the radial fields produced by the solenoids. Measures have been taken to mitigate these strong Lorentz forces: (1) extension of the sextupole length to place the racetrack ends far away from the axial coils and then to reduce the interactions between sextupole end and solenoids leading then to lengthy magnet and cryostat; (2) insertion of liquid metal bladders axially in between the straight sections of the sextupole to avoid any azimuthal deformation [69-70]. With these successful techniques, the air-cored classical Sext-In-Sol magnet is commonly used in the existing or under development high-field superconducting ECR ion sources, such as LNS SERSE [17], LBNL VENUS [13], RIKEN SCECR [22] and MSU SUSI [21].

To simplify the complex and lower the strong Lorentz interactions for easier magnet coil clamping, SECRAL uses a Sol-In-Sext magnet by reversing the positions of the solenoids and sextupole, in conjunction with a six segments cold-iron shell to concentrate the magnetic fields and minimize the stray fields outside the magnet assembly. The axial field strength generated by the solenoids is proportionally reciprocal to the average radius $R$ of the solenoids. Thus placing the solenoids inside the sextupole substantially reduces the average radius of the solenoids and the needed Ampere/Turns for the production of the same field strength on axis. This reduction is also beneficial as it gives lower fields outside the solenoids where the sextupole is located, leading then to weaker Lorentz interactions. This magnetic configuration allows then to build compact sextupole and cryostat. In addition, each of the six sextupole coils is bolted to one of the six iron segments for better mechanical support. Moreover, the iron can also play a role in attracting the sextupole coils toward 
the iron segment which results in a net outward force on all of the SECRAL's NbTi sextupole end, instead of alternately "in" and "out" in the case of a classical structure. Thanks to this Sol-in-Sext configuration that SECRAL is the most compact fully superconducting ECR ion source with no more than $1 \mathrm{~m}$ in both length and diameter of the cryostat. However, the main disadvantage of a Sol-In-Sext magnet is the inefficient utilization of the generated radial field. In addition, as the solenoids are located inside the hexapole, they experience high strength radial field leading to high stresses within the solenoid coils. However, these stresses can be easily overcome. To compensate for the radial field inefficiency in the Sol-In-Sext magnet, a high sextupole field is needed and the plasma chamber is slightly smaller than in the standard configuration. The warm bore of the SECRAL cryostat is slightly smaller than VENUS $(14 \mathrm{~cm}$ for SECRAL and $17 \mathrm{~cm}$ for VENUS), while the sextupole magnet length is much shorter for SECRAL $(73 \mathrm{~cm}$ for SECRAL and $92 \mathrm{~cm}$ for VENUS) [70]. Another unique feature of the Sol-In-Sext magnet structure is the use of a cold-iron shell to enhance the radial field and also to minimize the stray field outside the magnet assembly which can easily reach less than $50 \mathrm{G}$. Such a low stray field leads to a small interaction between the magnets and the outer iron yoke of the cryostat, which is benefiting for the magnet suspension and for installations of the cryocoolers and high Tc current leads inside the cryostat.

In addition to all features mentioned above, the clamping of the SECRAL magnet is rather simplified thanks to rather weak Lorentz forces. Unlike the classical magnet fabrication, in which complex bladders and formers between the sextupole and solenoids have to be used, the clamping used in the Sol-In-Sext magnet is simply a four-aluminum-sleeve enclosing the segmented iron shell to provide the needed prestress by their different thermal contractions after the system cooled down. When SECRAL is energized, the magnetic forces experienced by the six iron segments will add additional self-clamping force to the magnet assembly resulting in a rugged superconducting magnet, as shown in Fig. 7. Each of the six superconducting racetrack coils is wound around a piece of iron pole in the center to boost the pole field by more than $2 \mathrm{kG}$. Stainless steel wedges are axially inserted in between the adjacent sextupole coils to make them more rigid. Each of the sextupole coils is bolted to one of the six iron segments of the outer shell which covers the iron pole and the sextupole coil for easier magnet clamping and field concentration. The three axial solenoid coils are wound onto a stainless steel bobbin to prevent excessive deformation of the sextupole assembly under large magnetic force. Figure 8 shows the fabricated magnet assembly with the detailed coil structure.

The mirror magnetic field of SECRAL is designed according to the high mirror ratio magnetic profiles determined by the so-called high-B mode proposed by Gammino [56,60-61] and the magnetic field scaling laws

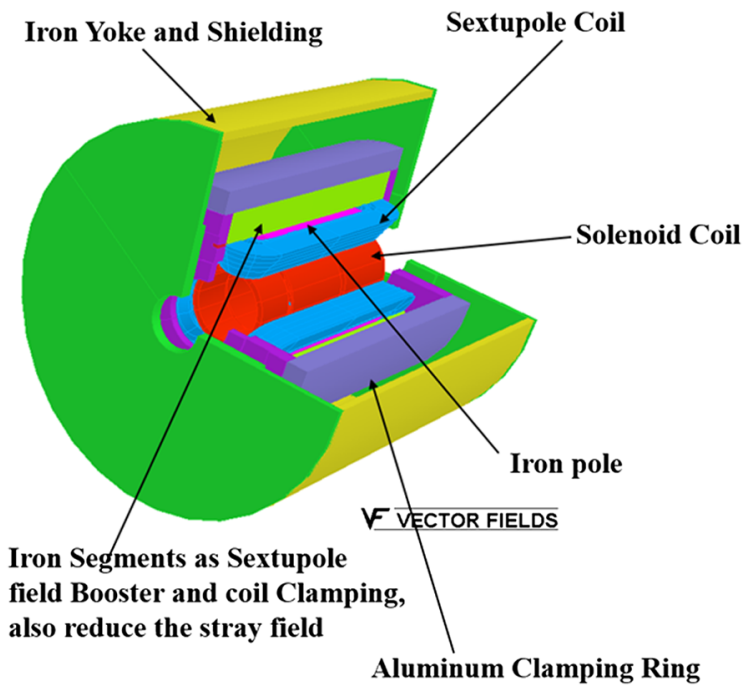

FIG. 7. SECRAL magnet structure and superconducting coil configuration.

[62]. It is now able to generate maximum axial fields of about $3.6 \mathrm{~T}$ at injection $\left(B_{\text {inj }}\right)$ and $2.0 \mathrm{~T}$ at extraction $\left(B_{\text {ext }}\right)$ with a mirror field peak distance of $420 \mathrm{~mm}$, and a maximum sextupole radial field of $2.0 \mathrm{~T}\left(B_{\text {rad }}\right)$ at the plasma chamber inner wall, to run this ECRIS at 24 and/or $28 \mathrm{GHz}$. The SECRAL magnetic profile agrees with today's scaling laws determined for a single frequency

(a)

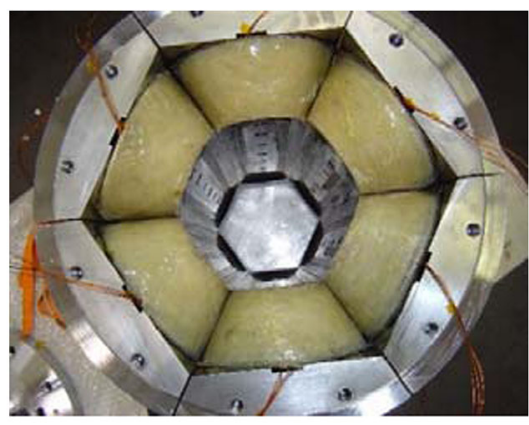

(b)

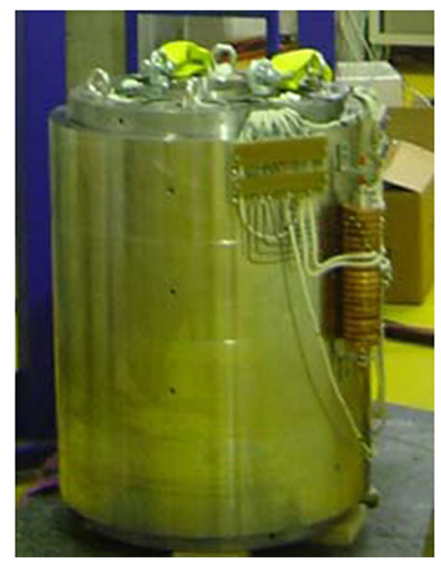

FIG. 8. Fabricated SECRAL magnet assembly and its detailed coil structure. 

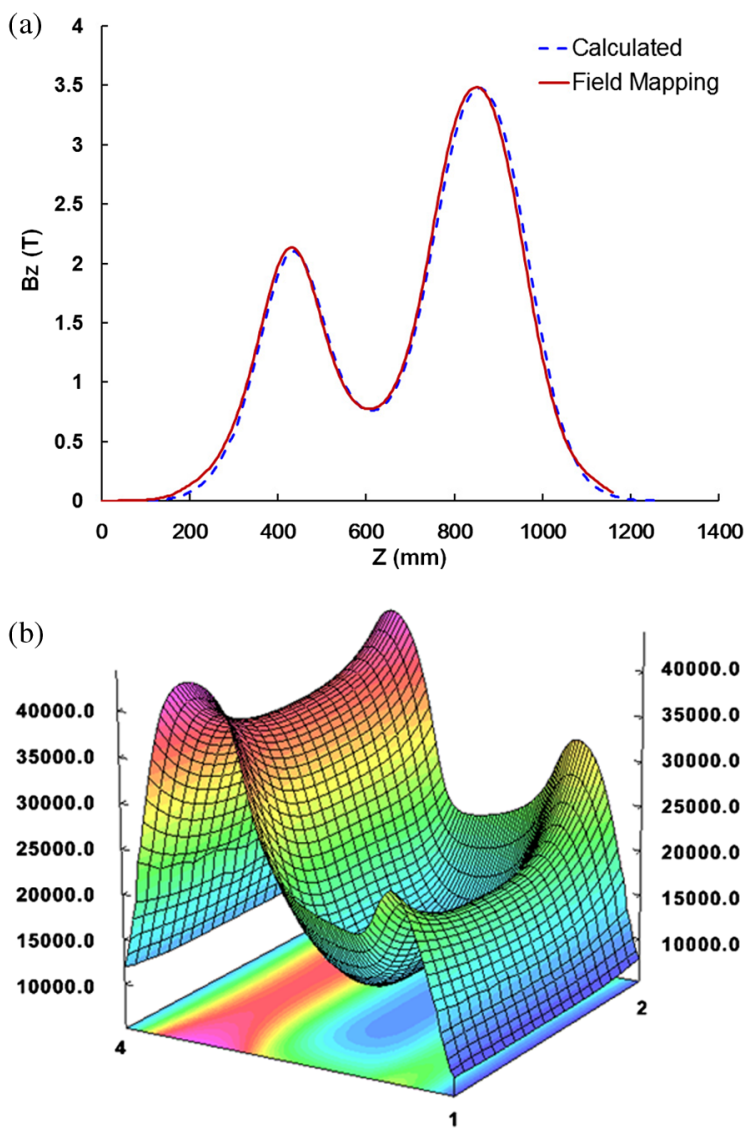

FIG. 9. SECRAL axial magnetic field distribution. (a) Designed axial mirror magnetic field $\left(B_{z}\right)$ distribution on the axis for SECRAL 24-28 GHz operation. (b) 3D field distribution at the $\mathrm{X}-\mathrm{Z}$ plane in the plasma chamber.

heating. The designed and measured axial field profile, and the total field distribution calculated by Opera-3D, at a plane cutting along the central line between two poles through the plasma chamber are shown in Fig. 9. As the axial minimum-B value $\left(B_{\min }\right)$ can vary from $0.5 \mathrm{~T}$ up to $0.8 \mathrm{~T}$, SECRAL could be run at a frequency ranging from $18 \mathrm{GHz}$ up to $28 \mathrm{GHz}$ and can advantageously use the double frequency heating technique. The resonance length on axis is about $120-130 \mathrm{~mm}$ for SECRAL for $24-28 \mathrm{GHz}$ operation. On the other hand, the minimum-B position $\left(B_{\min }\right)$ is not located at the center of the plasma chamber, but at several centimeters closer to the plasma electrode in order to achieve an efficient extraction of highly charged ion beams. A detailed distribution analysis of the threedimensional magnetic field does not show any so-called "magnetic holes" along the plasma chamber walls, which could lead to severe concentration of hot electron dumping and to a high level of $\mathrm{x}$-ray radiation in a small location damaging the chamber and the high voltage insulator. The distance between the magnetic field peak at the extraction $B_{\text {extr }}$ and the first focusing solenoid lens is designed as short as possible so that extracted beam could be focused as soon as possible to avoid beam blowup.
The SECRAL magnet assembly is immersed and cooled down in a liquid helium bath. The precooling to $30-50 \mathrm{~K}$ is achieved by the use of one stage cryocooler at the thermal radiation shields surrounding the liquid helium reservoir. Five high Tc current leads serve both as thermal insulators and electric continuity to the $4.2 \mathrm{~K}$ cold mass. They are mounted within the cryostat service turret and their high temperature ends are thermally linked to the cryocooler through a $30-50 \mathrm{~K}$ termination. The total heat load on the liquid helium reservoir is less than $1 \mathrm{~W}$ at $4.2 \mathrm{~K}$ and the liquid helium consumption rate measurement is less than $1.5 \mathrm{l} / \mathrm{h}$. The magnet had finally reached $100 \%$ of the design fields after 13 quenches at ACCEL company and five quenches at IMP during the user' site test.

\section{Microwave coupling}

It is crucial for any high performance ECR ion source to efficiently couple microwave power into the plasma. To do so, SECRAL is designed with the possibility to use the commonly adopted of double-frequency heating. In the case of a single frequency heating at $18 \mathrm{GHz}$, like the wave launching scheme commonly used in ECR ion sources [17,25,69-72], traditional off-axis rectangular waveguides (WR62) are used to launch the microwaves into the plasma. However, as the commercial klystron amplifier is limited to $2 \mathrm{~kW}$, two separate microwave generators and waveguides are used in SECRAL, as shown in Fig. 10. This parallel $18 \mathrm{GHz}$ microwave launching scheme should be more efficient than one line since the plasma itself could combine and absorb the microwave power effectively in such a case [30].

On the other hand, even if SECRAL can efficiently run at $18 \mathrm{GHz}$, a $24 \mathrm{GHz}$ heating is more suitable for this machine, according to its magnetic field profile. In the past, $28 \mathrm{GHz}$ microwave coupling to an ECR ion source has been successfully demonstrated with SERSE [17].

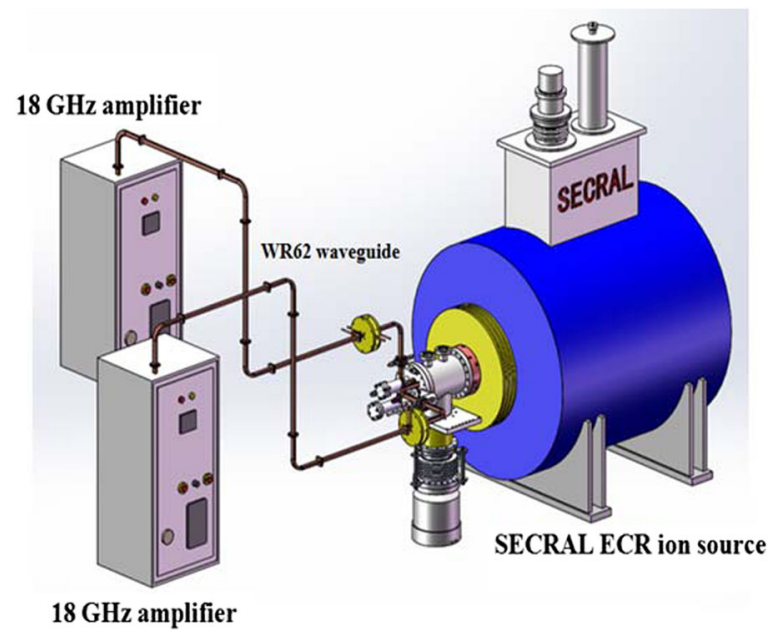

FIG. 10. SECRAL double waveguides coupling system both at $18 \mathrm{GHz}$. 
This success has established a base for coupling $28 \mathrm{GHz}$ microwaves into the high field superconducting ECR ion sources. Several years later, through the development of LBL-VENUS, a great number of technical challenges have been overcome to safely launch rf power larger than $6 \mathrm{~kW}$ [13]. For SECRAL, the $24 \mathrm{GHz}$ launching is similar to that designed for SERSE and VENUS at $28 \mathrm{GHz}$ : an oversized circular waveguide is capable of transmitting $7 \mathrm{~kW}$ from the gyrotron to the plasma. Figure 11 shows the scheme for double-frequency $(24+18 \mathrm{GHz})$ heating wave launching into SECRAL.

The $24 \mathrm{GHz}$ gyrotron system, built by GYCOM, Russia, is capable of transmitting the maximum power of the gyrotron, up to $7 \mathrm{~kW}$ in $\mathrm{TE}_{12}$ mode [73]. Similarly to the previous $28 \mathrm{GHz}$ lines, an arc detector is installed on the microwave transport line to detect any spark on the microwave window, and a bidirectional coupler measures both forward and reflected power. A mode converter converts the $\mathrm{TE}_{12}$ waves from the gyrotron into $\mathrm{TE}_{01}$ waves before being launched into the plasma chamber. A mode filter in the transport line based on selective power absorption of nonsymmetrical modes prevents the gyrotron from any reflected waves [73]. A $90^{\circ}$ quasioptical mirror bend is used to guide the microwave power by $90^{\circ}$ from the microwave generator line to the ion source injection port. Two mechanical compensators are installed to compensate for any thermal expansion in the transmission line and to tolerate small errors of the waveguide alignment. A $30 \mathrm{kV}$ dc break is placed between the mode convertor and the microwave window made of water-cooled boron-nitride separates the source vacuum from atmosphere pressure.

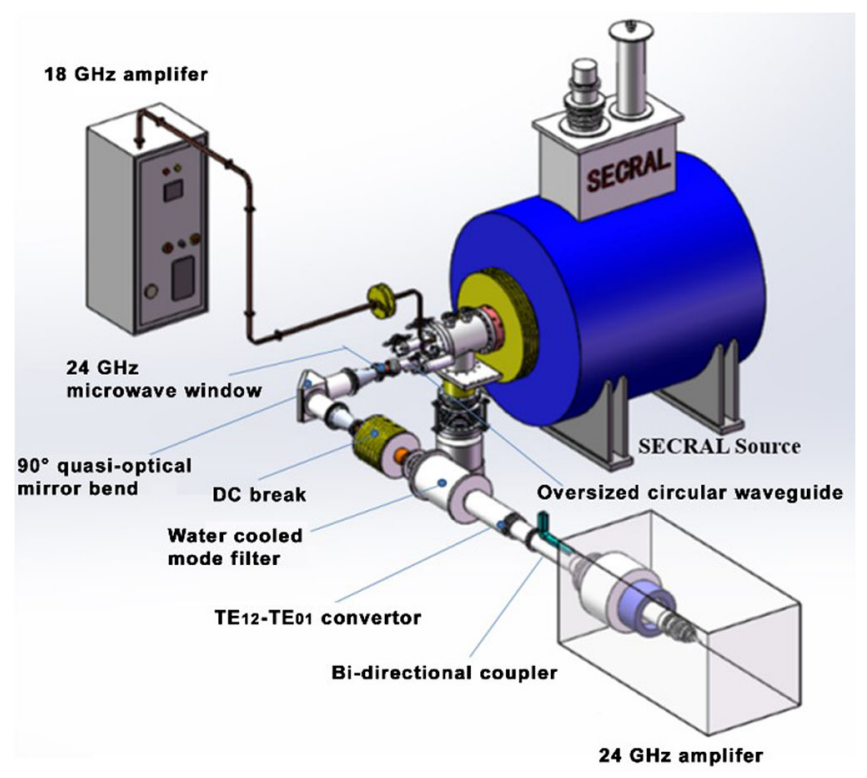

FIG. 11. SECRAL microwave coupling system with $24+$ $18 \mathrm{GHz}$ double frequency heating.

\section{COMMISSIONING AND PERFORMANCE STUDY}

\section{A. SECRAL milestones}

SECRAL started its maiden voyage with plasma energized by microwaves of $18 \mathrm{GHz}$ in August 2005 [27]. While many of these kinds of sources undergo 3-5 years of commissioning to optimize performance before serving the accelerators, SECRAL has been routinely delivering a great variety of highly charged heavy ion beams to the HIRFL accelerator facility since May 2007 [30]. SECRAL's performance, i.e. charge state, beam intensity and stability, has been continuously improved, especially more recently thanks to the use of new techniques [27-35].

Listed below are the milestones of the SECRAL development: (i) September 2000, the project was approved. (ii) April 2002, the magnet fabrication was contracted with ACCEL. (iii) August 2005, the first beam was produced at heating microwave of $18 \mathrm{GHz}$. (iv) 2005-2006, SECRAL was Commissioned at $18 \mathrm{GHz}$ and achieved $505 \mathrm{e} \mu \mathrm{A}$ of ${ }^{129} \mathrm{Xe}^{20+}$ and $101 \mathrm{e} \mu \mathrm{A}$ of ${ }^{129} \mathrm{Xe}^{30+}$. (v) May 2007, the first beam was delivered to HIRFL accelerator. (vi) October 2008, SECRAL was tested with $18+14.5 \mathrm{GHz}$ double frequency heating and aluminum chamber for highly charged ion beam production. (vii) August 2009, the first beam was produced at heating microwave of $24 \mathrm{GHz}$. (viii) December 2009, 3500 hours of beam was delivered to HIRFL accelerator. (ix)July 2011, SECRAL was tested with 3-5 kW microwave power at $24 \mathrm{GHz}$ and achieved $236 \mathrm{e} \mu \mathrm{A}$ of ${ }^{129} \mathrm{Xe}^{30+}$ and $242 \mathrm{e} \mu \mathrm{A}$ of ${ }^{209}{ }^{\mathrm{Bi}^{31+}}$. (x) September $2011,{ }^{238} \mathrm{U}^{32+}$ beam was firstly delivered to HIRFL accelerator. (xi) December 2011, 8000 hours of beam was delivered to HIRFL accelerator. (xii) March 2013, SECRAL was tested with 3-4 kW microwave power at $24+18 \mathrm{GHz}$ double frequency heating and achieved $396 \mathrm{e} \mu \mathrm{A}$ of ${ }^{209} \mathrm{Bi}^{31+}$ and $202 \mathrm{e} \mu \mathrm{A}$ of ${ }^{238} \mathrm{U}^{33+}$. (xiii) December 2013, 15000 hours of beam was delivered to HIRFL accelerator. (xiv) April 2014, SECRAL was tested with $5 \mathrm{~kW}$ microwave power at $24+18 \mathrm{GHz}$ double frequency heating and achieved $680 \mathrm{e} \mu \mathrm{A}$ of ${ }^{209} \mathrm{Bi}^{31+}$ and $10 \mathrm{e} \mu \mathrm{A}$ of ${ }^{209} \mathrm{Bi}^{50+}$. (xv) March 2015, SECRAL was tested with $8 \mathrm{~kW}$ microwave power at $24+18 \mathrm{GHz}$ double frequency heating and achieved $1.4 \mathrm{emA}$ of ${ }^{40} \mathrm{Ar}^{12+}$ and $1.1 \mathrm{emA}$ of ${ }^{129} \mathrm{Xe}^{26+}$. (xvi) July 2016, 25000 hours of beam was delivered to HIRFL accelerator. (xvii) June 2017, 28000 hours of beam was delivered to HIRFL accelerator.

\section{B. Commissioning at $18+14.5 \mathrm{GHz}$ double-frequency heating}

In the initial commissioning the SECRAL plasma was energized by microwaves of $18 \mathrm{GHz}$ with the production of a good number of gaseous and metallic ion beams, such as oxygen, argon, calcium, iron, nickel, krypton, xenon, lead, bismuth and uranium. Though the major focus of the commissioning was on gaseous ion beams since gases are 
much easier to be introduced into the source, high charge state ion beams of Ar, Xe and Bi represent SECRAL's production capability on the light, intermediate and heavy elements, respectively.

Base vacuum (without plasma) achieved in SECRAL was $4.0 \times 10^{-8}$ mbar at the source injection region, $3.0 \times$ $10^{-8}$ mbar at the extraction region and $1.0 \times 10^{-8}$ mbar at the beam line. During the commissioning, two different plasma chambers were tested, one made of stainless steel with $\varnothing 126 \mathrm{~mm}$ inner diameter, while the other one was made of aluminum with $\varnothing 116 \mathrm{~mm}$ inner diameter. As already mentioned, a $1.5 \mathrm{~mm}$ thick Ta shielding sleeve encloses the plasma chamber to reduce the x-ray irradiation damage to the high voltage insulator, following the experience of VENUS at LBNL [68].

During initial SECRAL commissioning at $18 \mathrm{GHz}$, the source was equipped with a stainless steel plasma chamber and one microwave generator with $1.7 \mathrm{~kW}$ power at maximum. Good performances were obtained and showed no beam current saturation with microwave power. This is understandable according to the plasma chamber volume. Then a second $18 \mathrm{GHz}$ generator was connected to the ion source. It was noticed that better beam stability is obtained with two waveguides for the same total power. As there is a resonance point inside the waveguides, it is necessary to avoid any outgassing and then the lower power launched in a waveguide. To some extent, for a total microwave power of, say, $6 \mathrm{~kW}$, it would be better to launch this power through four fundamental waveguides (WR62) or through one oversized waveguide (WR187). For the sake of simplicity, as this source is designed to run at a frequency higher than $18 \mathrm{GHz}$, we chose the multiple waveguides, as shown in Fig. 10. On the other hand, many tests with SECRAL show the total reflected power from two waveguides is less than that of a single waveguide at the same power level. Typically the total reflected power with two waveguides is less than $5 \%$, while the maximum reflected power with a single waveguide can be $10 \%$. With total input power ranging from 2.5 to $3.3 \mathrm{~kW}$, SECRAL could deliver, at $25 \mathrm{kV}, 810 \mathrm{e} \mu \mathrm{A}$ of ${ }^{16} \mathrm{O}^{7+}$ and $505 \mathrm{e} \mu \mathrm{A}$ of ${ }^{129} \mathrm{Xe}^{20+}$ [28]. For that, the optimum magnetic field profile was $B_{\text {inj }}=2.2 \mathrm{~T}, B_{\min }=0.47 \mathrm{~T}$ and $B_{\text {rad }}=1.1-1.2 \mathrm{~T}$, $B_{\text {ext }}=1.27-1.36 \mathrm{~T}$. Moreover, beam intensity increases linearly with the microwave power and showed no saturation indicating higher microwave power would lead to more intense beams. In spring of 2009, after more than 20 days of continuous ${ }^{129} \mathrm{Bi}^{31+}$ beam delivery to the HIRFL cyclotrons, an exploration was carried out for the production of very highly charged bismuth beams. Very impressive performance was obtained at $2.6 \mathrm{~kW}$, like $150 \mathrm{e} \mu \mathrm{A}$ of ${ }^{209} \mathrm{Bi}^{31+}, 22 \mathrm{e} \mu \mathrm{A}$ of ${ }^{209} \mathrm{Bi}^{41+}$ and $1.5 \mathrm{e} \mu \mathrm{A}$ of ${ }^{209} \mathrm{Bi}^{50+}$ [32]. To do so, the production of such highly charged heavy ion beams requires substantially high magnetic fields: $B_{\text {inj }}=2.5-2.6 \mathrm{~T}, B_{\min }=0.5 \mathrm{~T}, B_{\mathrm{rad}}=$ $1.3 \mathrm{~T}$ and $B_{\text {ext }}=1.26-1.35 \mathrm{~T}$. Figure 12 shows the charge

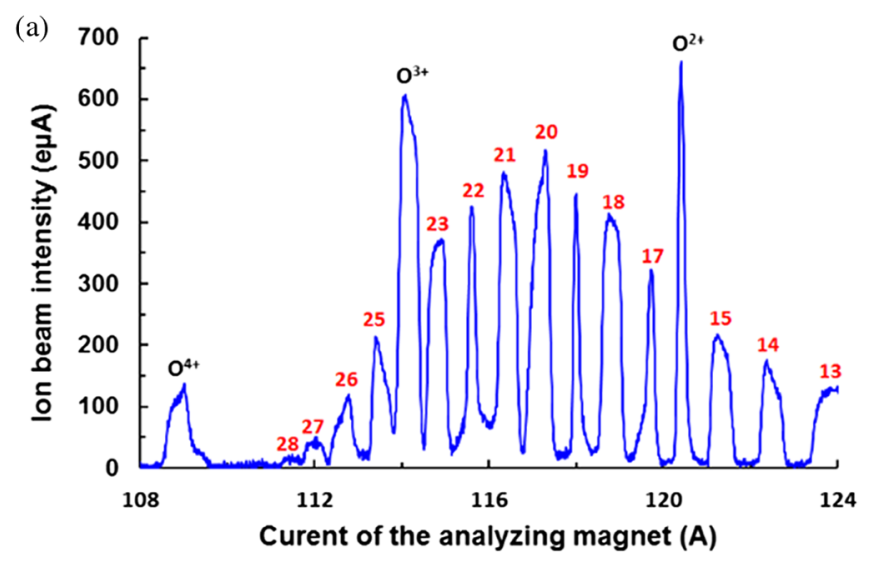

(b)

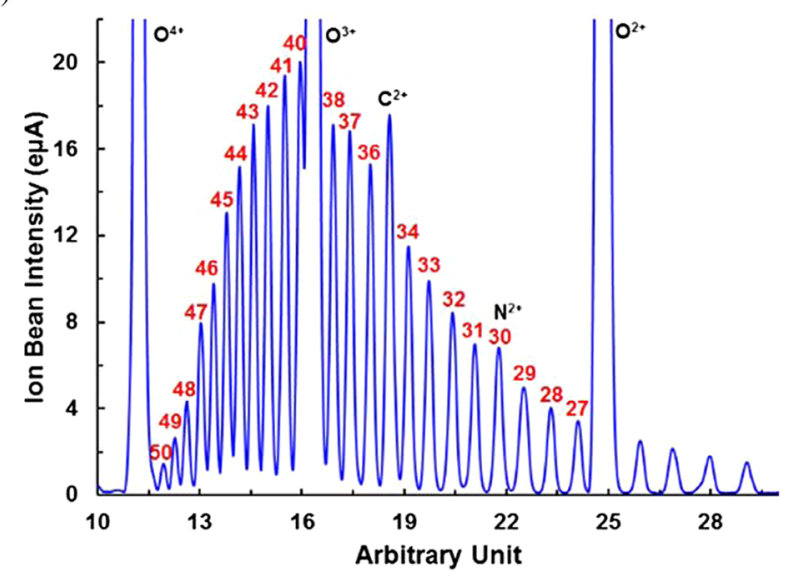

FIG. 12. CSD spectrum with the source optimized for ${ }^{129} \mathrm{Xe}^{20+}$ and ${ }^{209} \mathrm{Bi}^{50+}$. (a) Xenon CSD spectrum with the source optimized for ${ }^{129} \mathrm{Xe}^{20+}$ at $2.9 \mathrm{~kW}$ of $18 \mathrm{GHz}$ microwave power and $25 \mathrm{kV}$ extraction voltage. (b) Bismuth CSD spectrum with the source optimized for ${ }^{209} \mathrm{Bi}^{50+}$ at $2.6 \mathrm{~kW}$ of $18 \mathrm{GHz}$ microwave power and $25 \mathrm{kV}$ extraction voltage.

state distribution (CSD) with the source optimized for ${ }^{129} \mathrm{Xe}^{20+}$ and ${ }^{209} \mathrm{Bi}^{50+}$.

Later on, SECRAL was commissioned with both the stainless steel chamber and the aluminum chamber at $18 \mathrm{GHz}$ as well as $18+14.5 \mathrm{GHz}$ double frequency heating. As already noticed with another source, a stainless steel chamber gives better results in terms of beam intensity and stability than an aluminum chamber for medium charge states such as $\mathrm{Ar}^{14+}, \mathrm{Xe}^{20+}$ and $\mathrm{Xe}^{27+}$, even with $18+14.5 \mathrm{GHz}$ double frequency heating. Figure 13(a) illustrates beam intensity evolution of ${ }^{129} \mathrm{Xe}^{27+}$ as a function of microwave power for two plasma chamber materials at $18 \mathrm{GHz}$, and at $18+14.5 \mathrm{GHz}$ [32]. Here also, there is no saturation with rf power. However, the beam intensity enhancement with the aluminum chamber at $18+14.5 \mathrm{GHz}$ double frequency heating for very high charge state of xenon beam is quite obvious and significant, as shown in Fig. 13(b) [32], where the beam intensity ratios were normalized to per kilowatt $\left(I_{q} / P_{r f}\right)$ microwave 

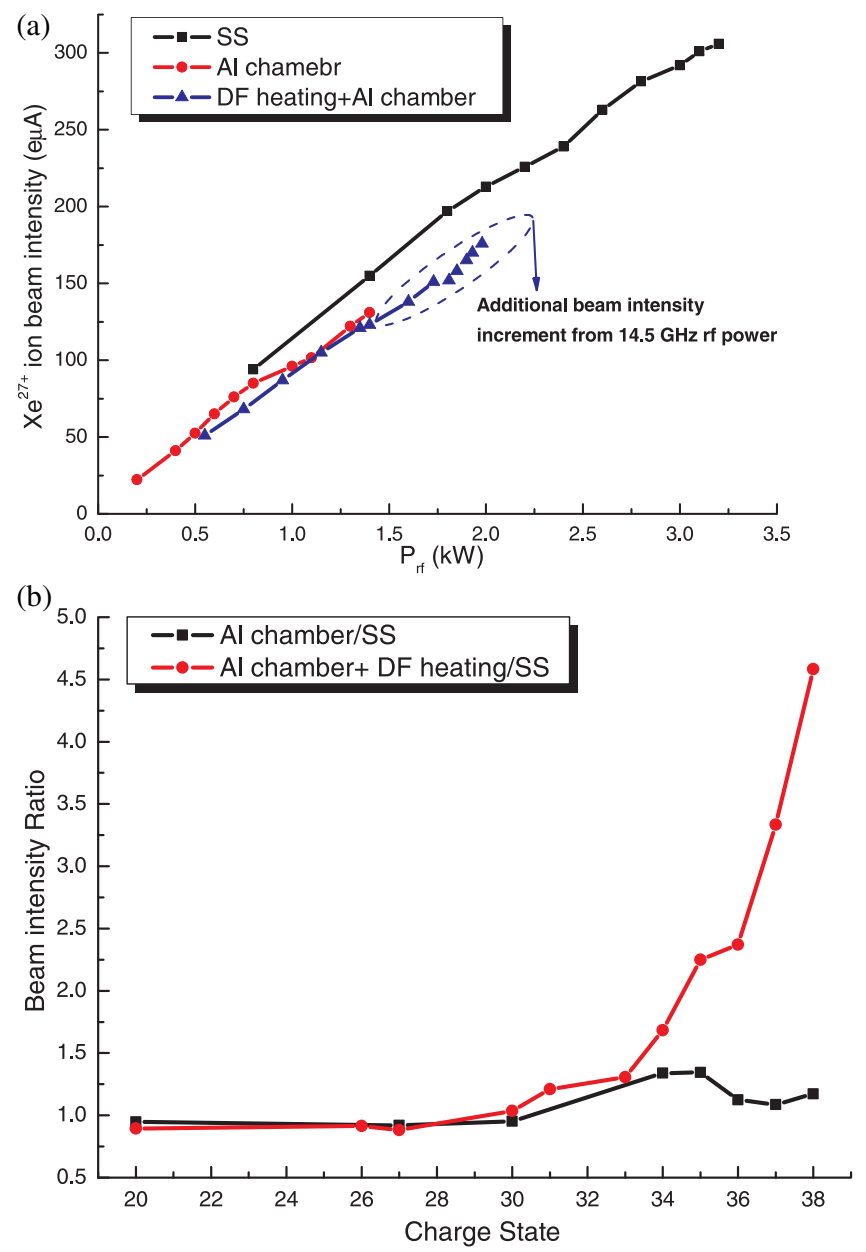

FIG. 13. Xenon beam intensity study with different chamber and microwave power. (a) ${ }^{129} \mathrm{Xe}^{27+}$ beam intensity evolution as a function of microwave power and comparison among stainless steel (SS) chamber at $18 \mathrm{GHz}$, aluminum (Al) chamber at $18 \mathrm{GHz}$, and aluminum chamber at $18+14.5 \mathrm{GHz}$. (b) Xenon beam intensity enhancement with aluminum chamber at $18+14.5 \mathrm{GHz}$ double frequency heating.

power. It is worth pointing out that plasma and beam stability at $18+14.5 \mathrm{GHz}$ double-frequency heating with the aluminum chamber is much more improved than the case of $18 \mathrm{GHz}$ single frequency with an aluminum chamber, as demonstrated decades ago at LBL [74]. The reason for improvement of plasma and beam stability by the double frequency heating might be related to suppression of electron cyclotron instability suggested by Skalyga [51].

\section{Bismuth and uranium beams with $24+18 \mathrm{GHz}$ heating waves}

In a third step of source commissioning, after the arrival of the $24 \mathrm{GHz}$ gyrotron in August 2009, SECRAL has been operating at $24+18 \mathrm{GHz}$. Very extensive source tuning on bismuth beams was conducted at various conditions to study the SECRAL capability and to determine the optimum parameters for the production of the very heavy ions. Bismuth was chosen because its mass is close to uranium, its vapor is easy to produce, it is chemically stable as compared to uranium and it is not radioactive.

Two different ovens are used to feed bismuth vapor [34]. The first one is an oven enclosed by resistive heating coil with maximum operation temperature of $1600^{\circ} \mathrm{C}$ but with moderate material loading capacity. The second one is a low temperature oven constructed with a large load crucible for long term operations and a commercial $100 \mathrm{~W}$ "WattFlex Cartridge Heater" for maximum oven operating temperature of $700^{\circ} \mathrm{C}$. This last low temperature oven is a duplicate of the LBNL one and is sufficient to create Bi vapor [75-76].

The experiment with bismuth beams was carried out in two stages at two different total microwave power, 3-4 and 4-6 kW.

Bismuth beam tests with microwave power of 3-4 kW focused on the production of ion beams of charge states from 30 to 55 with the use of the aluminum plasma chamber (ID $=116 \mathrm{~mm}$ ) and the first oven. The maximum beam currents achieved were $242 \mathrm{e} \mu \mathrm{A}$ of ${ }^{209} \mathrm{Bi}^{31+}$ and $160 \mathrm{e} \mu \mathrm{A}$ of ${ }^{209} \mathrm{Bi}^{36+}$ at $2.5 \mathrm{~kW}$ power of $24 \mathrm{GHz}$ plus $0.4 \mathrm{~kW}$ power of $18 \mathrm{GHz}$. In that case, the magnetic field configuration was $B_{\text {rad }}=1.6 \mathrm{~T}, B_{\text {inj }}=3.45 \mathrm{~T}$, $B_{\text {min }}=0.60 \mathrm{~T}$, and $B_{\text {ext }}=1.8 \mathrm{~T}$.

At higher microwave power $(3.8 \mathrm{~kW}$ power of $24 \mathrm{GHz}$ plus $1.3 \mathrm{~kW}$ of $18 \mathrm{GHz}$ ), a stainless steel chamber was used (ID $=120.5 \mathrm{~mm}$ ) together with the Cartridge Heater oven. Higher intensities and charge states were obtained like $396 \mathrm{e} \mu \mathrm{A}$ of ${ }^{209} \mathrm{Bi}^{31+}, 50 \mathrm{e} \mu \mathrm{A}$ of ${ }^{209} \mathrm{Bi}^{41+}$ and $4.3 \mathrm{e} \mu \mathrm{A}$ of ${ }^{209} \mathrm{Bi}^{50+}$. The magnetic field configuration was $B_{\text {rad }}=$ $1.71 \mathrm{~T}, B_{\text {inj }}=3.41 \mathrm{~T}, B_{\text {min }}=0.60 \mathrm{~T}$, and $B_{\text {ext }}=1.7 \mathrm{~T}$ [77]. The plasma stability was satisfactorily stable with the stainless steel chamber at microwave power of about $3 \mathrm{~kW}$ or lower, but it was difficult to keep the plasma stable at microwave power above $4 \mathrm{~kW}$. The plasma instabilities are likely caused by the strong anisotropy of hot electrons in the velocity space, i.e. the transverse velocity is much larger than the longitudinal one with respect to the magnetic field lines [38].

In a next step, the aluminum plasma chamber was reinstalled in conjunction with an improved cooling of all source components (biased disk, waveguides and microoven) in order to run the source above $4 \mathrm{~kW}$ without instabilities. Thanks to the aluminum wall coating effect and the secondary electron emission of this material, no instabilities were seen up to $6 \mathrm{~kW}$ of total power. The beam currents of highly charged bismuth ion beams were then increased by at least a factor of 2 when the source was able to operate at the total wave power of $5-6 \mathrm{~kW}$ compared to the operations with power less than $4 \mathrm{~kW}$, as shown in Fig. 14. A large number of record beam intensity of highly charged ions has been produced: $680 \mathrm{e} \mu \mathrm{A}$ of ${ }^{209} \mathrm{Bi}^{31+}, 320 \mathrm{e} \mu \mathrm{A}$ of ${ }^{209} \mathrm{Bi}^{36+}, 100 \mathrm{e} \mu \mathrm{A}$ of 


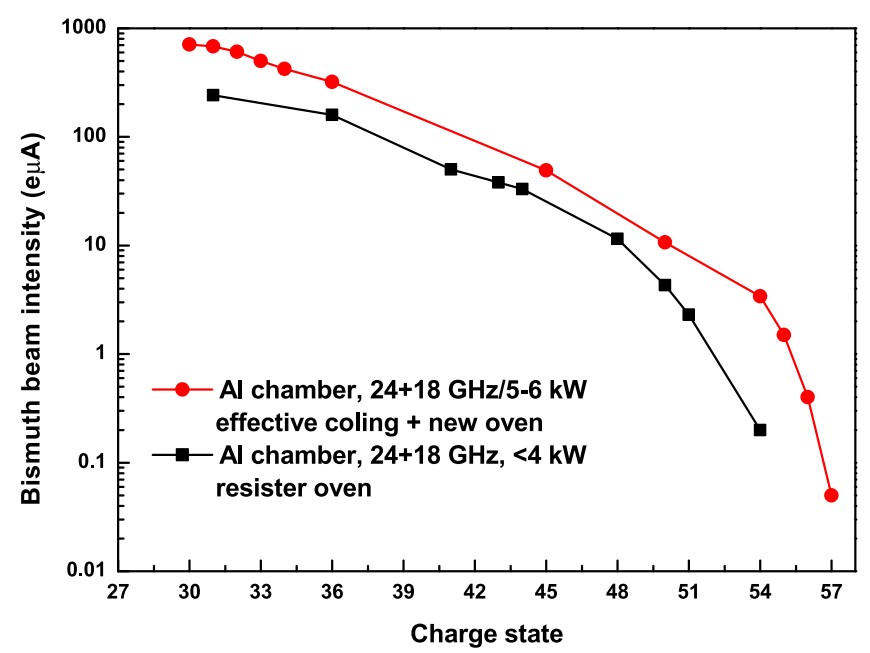

FIG. 14. Bismuth beam currents at the total microwave power 5-6 kW with a new oven and compared to those at the power less than $4 \mathrm{~kW}$.

${ }^{209} \mathrm{Bi}^{41+}$ (with $4.5 \mathrm{~kW}$ at $24 \mathrm{GHz}$ plus $1.2 \mathrm{~kW}$ at $18 \mathrm{GHz}$ ), and $10 \mathrm{e} \mu \mathrm{A}$ of ${ }^{209} \mathrm{Bi}^{50+}$ (with $3.3 \mathrm{~kW}$ at $24 \mathrm{GHz}$ plus $1.0 \mathrm{~kW}$ at $18 \mathrm{GHz}$ ). It should be pointed out that the temperature of the Cartridge Heater oven can be controlled accurately so that the evaporated bismuth vapor was stable during the beam tests.

Regarding the production of uranium beams with SECRAL, the sputtering method was used at $24+$ $18 \mathrm{GHz}$ double-frequency heating. Equipped with an aluminum chamber, SECRAL has produced $202 \mathrm{e} \mu \mathrm{A}{ }^{238} \mathrm{U}^{33+}$ (with $3.8 \mathrm{~kW}$ at $24 \mathrm{GHz}$ plus $1.0 \mathrm{~kW}$ at $18 \mathrm{GHz}$ ) [34]. Figure 15 shows the CSD spectra with the source tuned for ${ }^{209} \mathrm{Bi}^{31+},{ }^{209} \mathrm{Bi}^{50+}$ and ${ }^{238} \mathrm{U}^{33+}$, respectively.

SECRAL's production of bismuth and uranium beams with high power of $24+18 \mathrm{GHz}$ has demonstrated that the production of intense very heavy ion beams is achievable with an ECRIS.

\section{Production of record beam intensities by a new microwave coupling}

In 2000, for the first time, $28 \mathrm{GHz}$ microwaves were successfully launched into SERSE [17], a superconducting ECR ion source designed for operation at $18 \mathrm{GHz}$ but having a rather sufficient magnetic configuration to be run at higher frequency. The $28 \mathrm{GHz}$ microwaves generated by a gyrotron in $\mathrm{TE}_{02}$ mode were then converted into $\mathrm{TE}_{01}$ wave and transported in an oversize circular waveguide of conventional diameter of $32 \mathrm{~mm}$ before being launched into the ion source. All other $24-28 \mathrm{GHz}$ ECR sources have utilized the similar microwave coupling system, like VENUS [13], SECRAL [31], RIKEN-SCECR [22], SuSI [21], and so on. $\mathrm{TE}_{01}$ wave mode is used since losses along the waveguide are very low, theoretically zero. The electric field of the $\mathrm{TE}_{01}$ wave is unpolarized and circular having

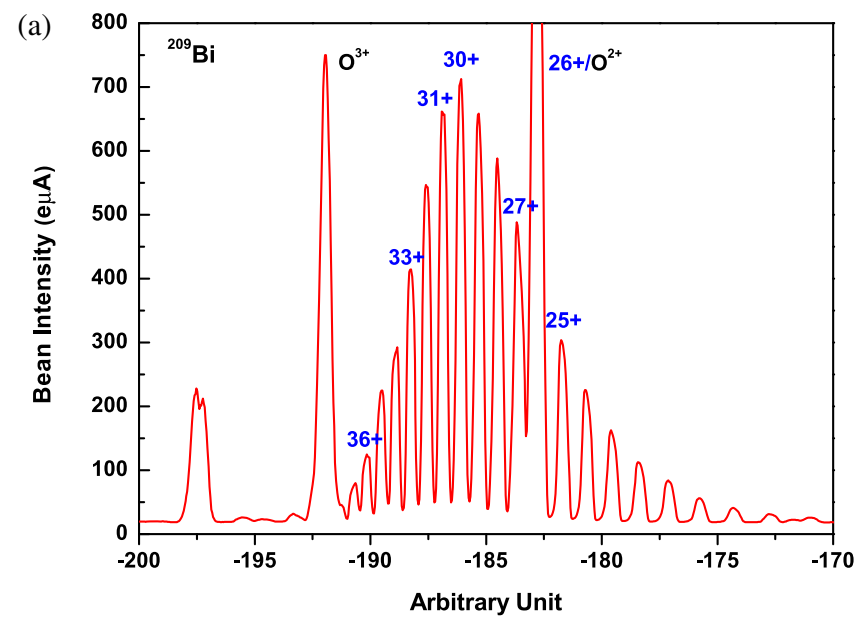

(b)

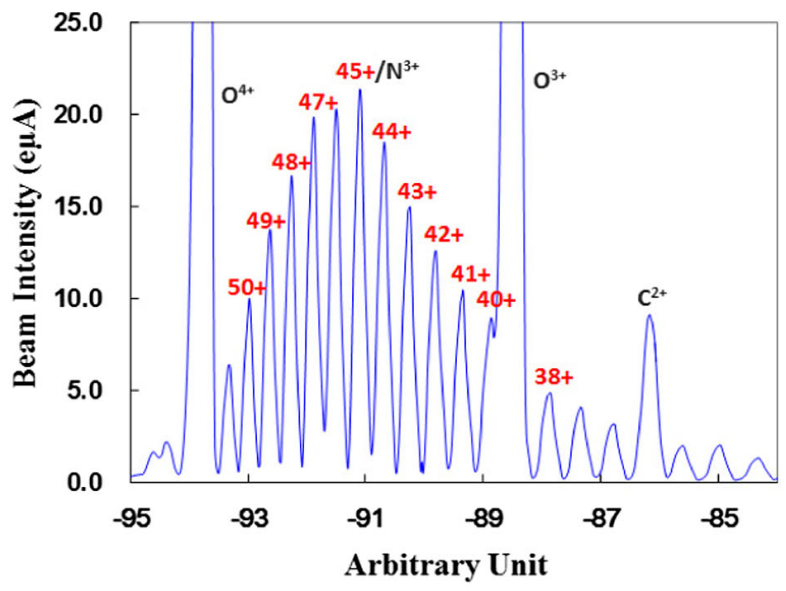

(c)

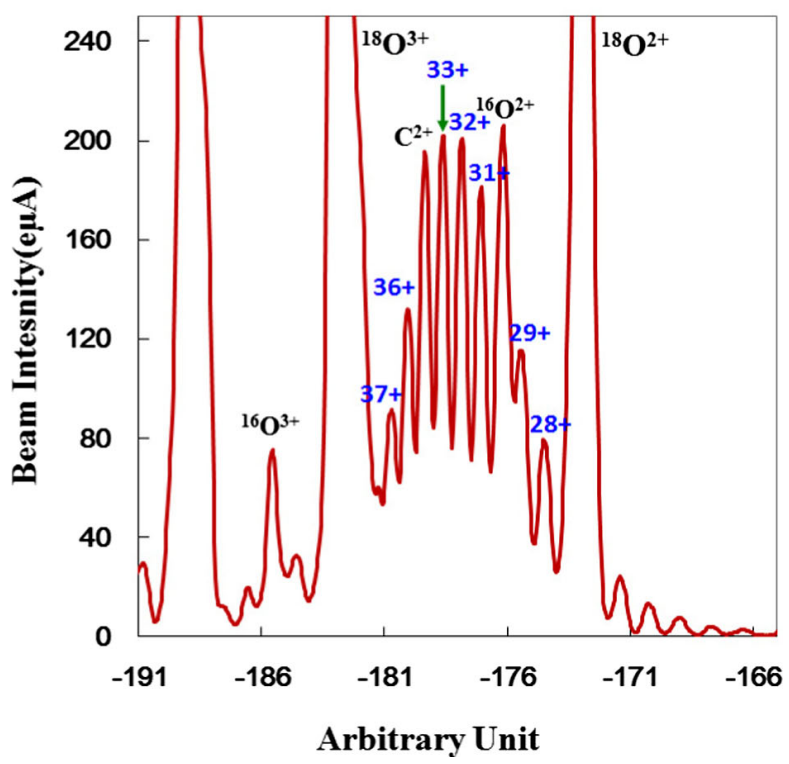

FIG. 15. CSD spectra with the source tuned for ${ }^{209} \mathrm{Bi}^{31+},{ }^{209} \mathrm{Bi}^{50+}$ and ${ }^{238} \mathrm{U}^{33+}$. (a) Bismuth CSD spectrum with the source optimized for ${ }^{209} \mathrm{Bi}^{31+}$ at total microwave power $5.1 \mathrm{~kW}$ of $24+18 \mathrm{GHz}$. (b) Bismuth CSD spectrum with the source optimized for ${ }^{209} \mathrm{Bi}^{50+}$ at total microwave power $4.3 \mathrm{~kW}$ of $24+18 \mathrm{GHz}$. (c) Uranium CSD spectrum with the source optimized for ${ }^{238} \mathrm{U}^{33+}$ at total microwave power $3.7 \mathrm{~kW}$ of $24+18 \mathrm{GHz}$. 

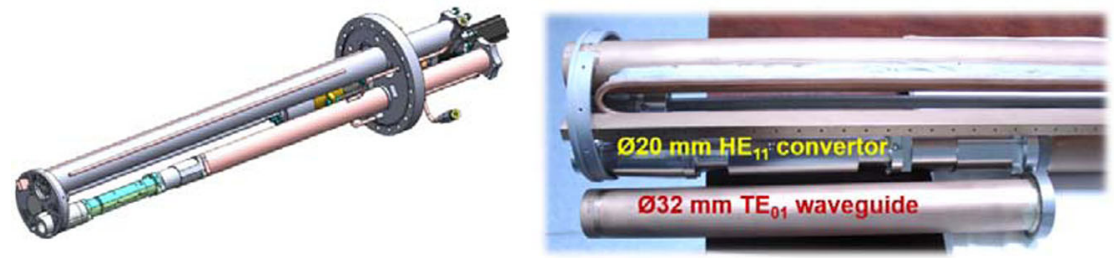

FIG. 16. Compact mode convertor from $\mathrm{TE}_{01}$ to $\mathrm{HE}_{11}$.

zero electric fields at the inner surface and axis of the waveguide, i.e. the power distribution at the waveguide center is also very low. To avoid this zero power on waveguide axis, Hitz proposed other launching $\mathrm{TE}_{11}$ and $\mathrm{HE}_{11}$ into ECR ion sources which could lead to more efficient coupling to the plasma [2]. The $\mathrm{HE}_{11}$ mode is polarized with a quasi-Gaussian power distribution being maximum at the center [78]. It is thought that the $\mathrm{HE}_{11}$ might be, like in fusion machines, more efficient for the ECR heating and would enhance the source performance. The $\mathrm{TE}_{01}-\mathrm{HE}_{11}$ microwave coupling was not explored until 2013, when Lyneis had designed and built, at LBNL, a $28 \mathrm{GHz} \mathrm{TE}_{01}-\mathrm{HE}_{11}$ mode convertor and carried out tests with VENUS. However, no improvement was observed with this new coupling [78].

A similar launching wave mode has been tested with SECRAL at $24 \mathrm{GHz}$ with a $\mathrm{TE}_{01}$ to $\mathrm{HE}_{11}$ mode convertor and microwave coupling system made of a snake waveguide and a corrugated waveguide [35,79]. However, due to the size of the convertor and the plasma chamber diameter (ID $=116 \mathrm{~mm}$ ), there was not enough space to house such a large convertor. Then, the original $\varnothing 32 \mathrm{~mm}$ circular waveguide was tapered down to $\varnothing 20 \mathrm{~mm}$, before the $\mathrm{TE}_{01}$ to $\mathrm{HE}_{11}$ mode convertor. This compact mode convertor developed by IMP is shown in Fig, 16. To have a meaningful comparison, an $\varnothing 20 \mathrm{~mm} \mathrm{TE} \mathrm{T}_{01}$ mode circular waveguide was also fabricated and tested with SECRAL.

Tests were carried out with SECRAL focusing on the production of highly charged argon and xenon ion beams, with three different launchings: standard $\varnothing 32 \mathrm{~mm} \mathrm{TE} \mathrm{T}_{01}$, $\emptyset 20 \mathrm{~mm} \mathrm{TE}{ }_{01}$ and $\varnothing 20 \mathrm{~mm} \mathrm{HE}_{11}$ waves, with the double frequency heating at $24+18 \mathrm{GHz}$. To get a good comparison between these launchings, SECRAL source parameters were optimized but kept as close to each operating wave as possible. Figure 17 illustrates the efficiency of these three launchings for ${ }^{129} \mathrm{Xe}^{27+}$, ${ }^{40} \mathrm{Ar}^{12+}$ and ${ }^{40} \mathrm{Ar}^{14+}$ with the same extraction voltage set at $25 \mathrm{kV}$. Figure 17 also demonstrates that whatever the wave coupling scheme, the beam intensities for the ions ${ }^{129} \mathrm{Xe}^{27+},{ }^{40} \mathrm{Ar}^{12+}$ and ${ }^{40} \mathrm{Ar}^{14+}$ keep increasing almost linearly with the input microwave power even up to $9 \mathrm{~kW}$ without saturation.

Table I compares the achieved ion beam intensity at similar wave power level for each of the launching schemes. The corresponding sextupole field at the chamber wall and the axial magnetic fields for the source tuning are also listed in Table I. These results have demonstrated that though the $\mathrm{HE}_{11}$ waves can produce about the same highly charged ion beams as the $\mathrm{TE}_{01}$ waves, no performance enhancements were obtained, as for VENUS [78]. On the other hand, beam tuning with the $\mathrm{HE}_{11}$ waves at high power appeared to be more difficult to generate a stable ECR plasma.

In addition to the results with the $\mathrm{HE}_{11}$ waves, Fig. 17 and Table I show the very good efficiency of the $\varnothing 20 \mathrm{~mm}$ $\mathrm{TE}_{01}$ wave coupling, even if the gain for the higher charge state ion beam like ${ }^{129} \mathrm{Xe}^{34+}$ is small. Moreover, beam tuning with the $\varnothing 20 \mathrm{~mm} \mathrm{TE}_{01}$ waveguide appears to be much easier than with the other launchings. Table I also
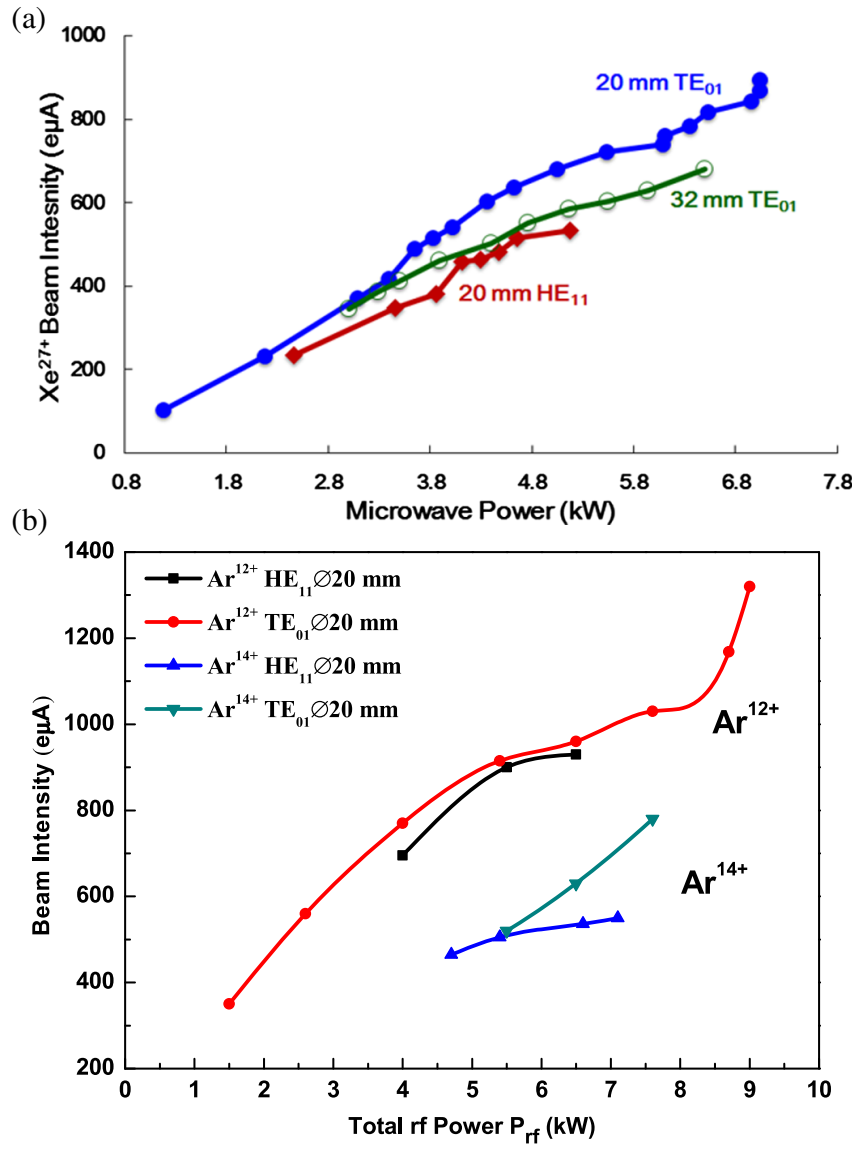

FIG. 17. Dependence of beam intensity on total microwave power at $24+18 \mathrm{GHz}$ coupled at different microwave coupling schemes. (a) ${ }^{129} \mathrm{Xe}^{27+}$ beam; (b) ${ }^{40} \mathrm{Ar}^{12+}$ and ${ }^{40} \mathrm{Ar}^{14+}$ beam. 
TABLE I. Comparison of typical beams and the beam intensities at the similar microwave power level by using different wave coupling schemes.

\begin{tabular}{lccccc}
\hline \hline Ion & $\mathrm{I}(\mathrm{e} \mu \mathrm{A})$ & $\mathrm{P}_{r f}(\mathrm{~kW}) 24+18 \mathrm{GHz}$ & $B_{\text {rad }}, B_{\text {inj }}, B_{\text {min }}, B_{\text {ext }}(\mathrm{T})$ & $\mathrm{V}_{\text {extr }}(\mathrm{kV})$ & $\mathrm{rf}$ coupling \\
\hline${ }^{129} \mathrm{Xe}^{27+}$ & 588 & $6+1.6$ & $1.65,3.45,0.58,1.66$ & 25 & $\mathrm{TE}_{01} \varphi 32$ \\
& 738 & $6+1.6$ & $1.61,3.40,0.58,1.68$ & $\mathrm{TE}_{01} \varphi 20$ \\
& 620 & $6+1.6$ & $1.63,3.31,0.53,1.62$ & $\mathrm{HE}_{11} \varphi 20$ \\
${ }^{129} \mathrm{Xe}^{30+}$ & 265 & $7+1.2$ & $1.66,3.50,0.60,1.80$ & 25 & $\mathrm{TE}_{01} \varphi 32$ \\
& 293 & $7+1.0$ & $1.65,3.49,0.62,1.94$ & & $\mathrm{TE}_{01} \varphi 20$ \\
& 235 & $7+1.7$ & $1.65,3.54,0.56,1.74$ & & $\mathrm{HE}_{11} \varphi 20$ \\
${ }^{129} \mathrm{Xe}^{34+}$ & 80 & $4.2+1.1$ & $1.66,3.43,0.63,1.81$ & 25 & $\mathrm{TE}_{01} \varphi 32$ \\
& 90 & $7+1.4$ & $1.65,3.50,0.60,1.82$ & & $\mathrm{TE}_{01} \varphi 20$ \\
& 25 & $6+1.5$ & $1.65,3.60,0.58,1.70$ & & $\mathrm{HE}_{11} \varphi 20$ \\
${ }^{40} \mathrm{Ar}^{12+}$ & 1300 & $6+1.7$ & $1.54,3.23,0.55,1.52$ & 26 & $\mathrm{TE}_{01} \varphi 20$ \\
& 1120 & $6+1.7$ & $1.43,3.30,0.52,1.60$ & & $\mathrm{HE}_{11} \varphi 20$ \\
${ }^{40} \mathrm{Ar}^{14+}$ & 630 & $5+1.5$ & $1.58,3.46,0.56,1.59$ & 25 & $\mathrm{TE}_{01} \varphi 20$ \\
& 516 & $5+1.5$ & $1.63,3.52,0.53,1.59$ & & $\mathrm{HE}_{11} \varphi 20$ \\
${ }^{40} \mathrm{Ar}^{16+}$ & 310 & $6+1.5$ & $1.65,3.50,0.60,1.70$ & 26 & $\mathrm{TE}_{01} \varphi 20$ \\
& 198 & $6+1.75$ & $1.66,3.46,0.59,1.70$ & & $\mathrm{HE}_{11} \varphi 20$ \\
\hline \hline
\end{tabular}

indicates that for all three types of launching, the magnetic field configuration is almost the same: $B_{\text {rad }} \sim 1.9 B_{\text {ecr }}$, $B_{\text {inj }} \sim 4.0 B_{\text {ecr }}, B_{\text {min }} \sim 0.67-0.73 B_{\text {ecr }}$, and $B_{\text {ext }} \sim 1.9-2.1 B_{\text {ecr }}$, where $B_{\text {ecr }}$ is the electron resonance field for $24 \mathrm{GHz}$ waves, i.e. $0.86 \mathrm{~T}$. This is consistent with the scaling laws determined with SERSE for one frequency heating $[17,62]$, as the second frequency mostly helps in plasma stabilization.

With the $\varnothing 20 \mathrm{~mm} \mathrm{TE}_{01}$ circular waveguide, SECRAL has produced again a large number of new record beams of highly charged ions, such as, $1420 \mathrm{e} \mu \mathrm{A}$ of ${ }^{40} \mathrm{Ar}^{12+}$, $846 \mathrm{e} \mu \mathrm{A}$ of ${ }^{40} \mathrm{Ar}^{14+}, 1100 \mathrm{e} \mu \mathrm{A}$ of ${ }^{129} \mathrm{Xe}^{26+}, 920 \mathrm{e} \mu \mathrm{A}$ of ${ }^{129} \mathrm{Xe}^{27+}, 322 \mathrm{e} \mu \mathrm{A}$ of ${ }^{129} \mathrm{Xe}^{30+}$ and $90 \mathrm{e} \mu \mathrm{A}$ of ${ }^{129} \mathrm{Xe}^{34+}$.

Figure 18 shows the CSD spectra at total microwave power $8.5 \mathrm{~kW}$ of $24 \mathrm{GHz}+18 \mathrm{GHz}$ double frequency heating with the $\varnothing 20 \mathrm{~mm} \mathrm{TE} 01$ circular waveguide when the source is optimized for ${ }^{40} \mathrm{Ar}^{12+}$ and ${ }^{129} \mathrm{Xe}^{30+}$. It is worth pointing out that for the first time for ${ }^{40} \mathrm{Ar}^{12+}$ and ${ }^{129} \mathrm{Xe}^{26+}$, the $1 \mathrm{emA}$ level has been reached and exceeded. The previous record beam intensities of ${ }^{40} \mathrm{Ar}^{12+}$ were $860 \mathrm{e} \mu \mathrm{A}$ by LBNL VENUS in 2006 [80] and ${ }^{129} \mathrm{Xe}^{26+}$ was $480 \mathrm{e} \mu \mathrm{A}$ by IMP SECRAL in 2009 [31].

The performance achieved recently with SECRAL has demonstrated that there is still potential in enhancing the performance of ECR ion sources by improving the microwave coupling. Speculative thought was that the $\mathrm{HE}_{11}$ waves with most of the energy concentrated on axis could benefit the ECR heating to improve the source performance, but surprisingly the tests in both SECRAL and VENUS reveal that it is not the case. The tests of the $\mathrm{HE}_{11}$ mode coupling with VENUS and SECRAL have once again raised the question: is the performance of an ECR ion source independent on the microwave mode? Further
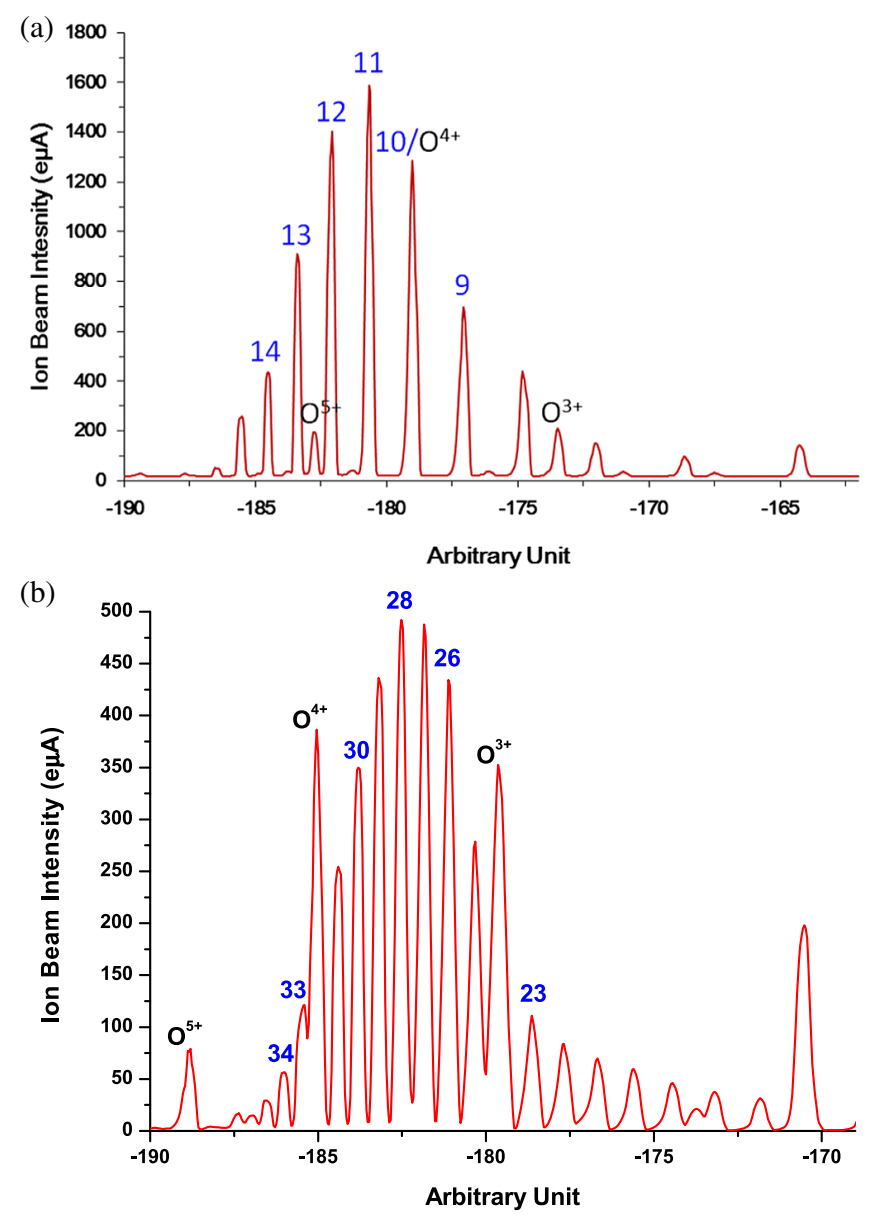

FIG. 18. CSD spectra at total microwave power $8.5-8.7 \mathrm{~kW}$ of $24+18 \mathrm{GHz}$ double frequency heating with the $\emptyset 20 \mathrm{~mm} \mathrm{TE}_{01}$ circular waveguide. (a) The SECRAL source optimized for ${ }^{40} \mathrm{Ar}^{12+}$. (b) The SECRAL source optimized for ${ }^{129} \mathrm{Xe}^{30+}$. 
theoretical and experimental studies should lead to a more definite conclusion.

SECRAL performance on the highly charged ion beams has been substantially improved by reducing the size of the $\mathrm{TE}_{01}$ waveguide down to $\varnothing 20[35,79]$. Later on, similar experiments were conducted at $28 \mathrm{GHz}$ LBNL VENUS in 2016 [65]; and strong intensity enhancements were noticed for highly charged oxygen, argon and krypton ion beams. The experiments with reduced size of the $\mathrm{TE}_{01}$ waveguide demonstrate that optimizing different ion beam production may require different launching size of the circular waveguide. The key reason might be related to absorption of the microwave power by the ECR plasma. Unfortunately the existing designed microwave coupling system is not able to measure the reflected power at 24-28 GHz with the oversize circular waveguide due to multimode transmission.

It is worth mentioning the explanation of Melin in the 12th ECRIS workshop [81] on the electron heating which may help with understanding of the experimental results. "It could be said that, the electron heating has to be perpendicular, with respect to the local magnetic field. The electron, moving back and forth along a magnetic field line, receives a kick in perpendicular velocity when crossing the resonance zone only if there is an electric field transversal with respect to the magnetic field. An electric field parallel to the magnetic field would cause the electron to fall in the loss-cone and to get lost rapidly. Nonetheless, as hot plasma is created close to the main axis, the direction is somewhat preferential and will be referred to below as the parallel direction. Thus it is preferable to have the $\mathrm{rf}$ wave launched parallel to this main axis, with an electric field perpendicular to this axis."

This is the case for all three types of launching studied here; however, as the electrons spiral along the magnetic field lines, one may easily suppose that the chances to get positive kicks of energy are larger with $\mathrm{TE}_{01}$ than with $\mathrm{HE}_{11}$. One also can imagine that chances are also better with smaller waveguide diameter, some further simulation and tests with SECRAL to study the microwave coupling are underway hoping to gain a better understanding.

\section{E. Microwave frequency and power effect}

The SECRAL data show one more time that performance of the highly charged ECR ion source is improved with microwave increase, provided that the magnetic confinement follows the well-established scaling laws for the main frequency heating. Geller's scaling law predicts the beam intensity $I_{q}$ of an ECR ion source is proportional to the square of the microwave frequency $\omega_{r f}$, and then proportional to $B_{\text {ecr }}$, while the mean charge state $\langle q\rangle$ increases with the microwave frequency according to the formula $\langle q\rangle \propto \log \omega_{r f} 3.5[1,58-59,82]$.

Performance of high field and high frequency ECR ion sources, such as LNS SERSE [17], LBNL VENUS [13],
IMP SECRAL [31], NSCL SuSi [21] and RIKEN SCECR [22], have validated a perspective of the development of ECR ion sources in terms of the scaling law prediction by continuously increasing the beam intensities and charge states. However, do those third generation ECR sources, operating at $24-28 \mathrm{GHz}$ with $5-10 \mathrm{~kW}$ high microwave power, still follow the scaling law prediction that the beam intensity is proportional to the square of the microwave frequency? Which parameter among the magnetic field, the microwave frequency and the microwave power, is more critical and dominant for the intense ion beam production of certain range of charge states? Effects of microwave frequency and power scaling at both $18+14.5 \mathrm{GHz}$ and $24+18 \mathrm{GHz}$ studied with SECRAL source are presented.

Figure 19 shows the best beam intensities of ${ }^{129} \mathrm{Xe}^{27+}$ achieved with SECRAL as a function of the injected power density for $18+14.5 \mathrm{GHz}$ and $24+18 \mathrm{GHz}$. As the hot plasma volume is delimited by the resonance surface, it is more relevant to assume that most of the microwave power is absorbed in this volume and not spread in the entire plasma chamber. This plasma volume delimited by the main resonance zone is roughly 0.51 at $24 \mathrm{GHz}$ and 0.381 at $18 \mathrm{GHz}$ for the source conditions set to get the $\mathrm{Xe}^{27+}$ beam intensities presented in Fig. 19. Also shown in this figure is an extrapolation from 18 to $24 \mathrm{GHz}$ with the frequency square. Above $7 \mathrm{~W} / \mathrm{cm}^{3}$, there is a remarkable coincidence between this extrapolation from $18 \mathrm{GHz}$ and the best $24 \mathrm{GHz}$ rf coupling, i.e. $\mathrm{TE}_{01}-\varnothing 20 \mathrm{~mm}$. This $7 \mathrm{~W} / \mathrm{cm}^{3}$ corresponds to $2.7 \mathrm{~kW}$ at $18 \mathrm{GHz}$ and $3.5 \mathrm{~kW}$ at $24 \mathrm{GHz}$.

On the other hand, below $7 \mathrm{~W} / \mathrm{cm}^{3}$, the situation at $24 \mathrm{GHz}$ is very different as beam intensities are identical for both 18 and $24 \mathrm{GHz}$. This means that the input power is not entirely absorbed by the plasma and is either reflected to the microwave generator or spread inside the plasma chamber. The way that the microwave transmission line is designed

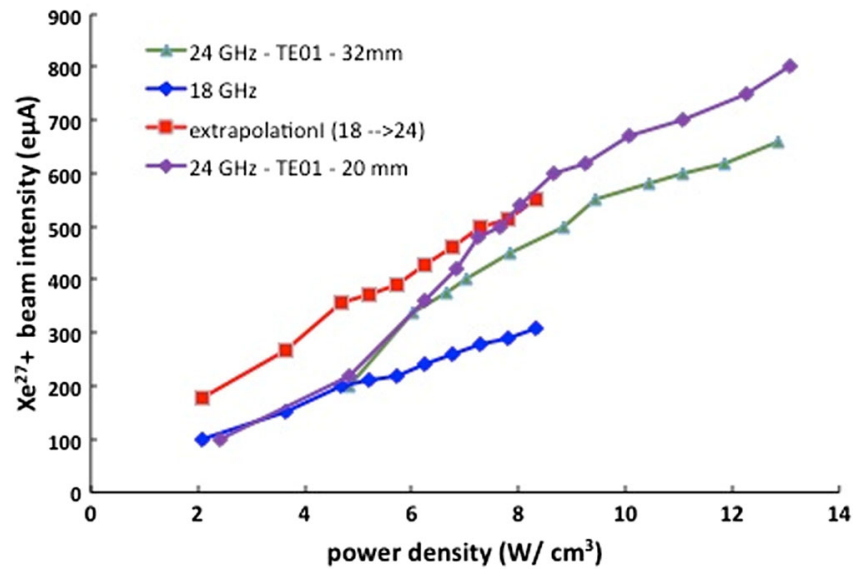

FIG. 19. Dependences of the best beam intensities of ${ }^{129} \mathrm{Xe}^{27+}$ on the total incident microwave power density at $24+18 \mathrm{GHz}$ and $18+14.5 \mathrm{GHz}$. 


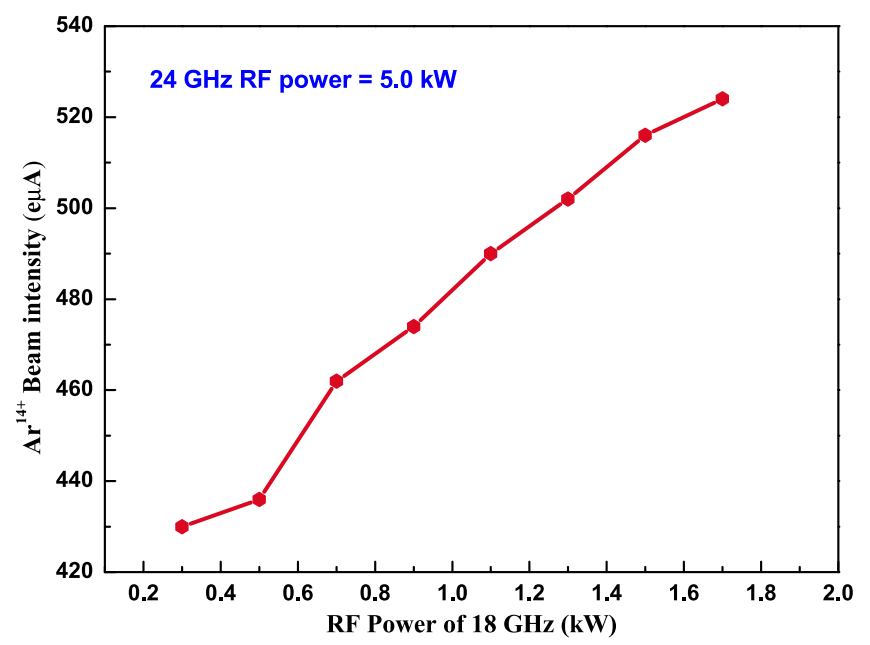

FIG. 20. ${ }^{40} \mathrm{Ar}^{14+}$ beam intensity dependence on microwave power of the second supplemental heating frequency $18 \mathrm{GHz}$ when the main frequency $24 \mathrm{GHz}$ power is fixed.

does not allow any measurement of the reflected power as the bidirectional coupler can only detect the $\mathrm{TE}_{02}$ mode. Nevertheless, from Fig. 19, one can notice that the $24 \mathrm{GHz}$ is efficient above $3.5 \mathrm{~kW}$. An explanation is given by Girard in the article [40] which shows that the absorbed power increases with the microwave wave electric field up to a maximum the plasma builds up, i.e. at low microwave power, the electron density is small and cannot absorb the total input power. Therefore, in the case of SECRAL, the buildup limit is about $7 \mathrm{~W} / \mathrm{cm}^{3}$. Another explanation and understanding could be given by Ivanov in the article [83] which points out that with increasing the microwave power the electrons are heated more and more, resulting in an increase of the ionization coefficients; meanwhile, the confinement time of the plasma decreases due to ion heating and an increase of the turbulence enhanced plasma transport to the walls. At low power, the beneficial effect of electron heating dominates. Thus, increasing the admitted power improves the performance of an ion source. At a certain power level, the increase of plasma losses due to transport balances the improvement due to electron heating, outweighing it when increasing the admitted power further [83]. Some significant studies on these issues were also conducted by Gammino, Mascali, Koivisto and Lyneis [43,84-87], which can be helpful for understanding the role of microwave coupling, effects of microwave frequency and power.

However, during some other experiments performed with $\operatorname{argon}$, for the production of ${ }^{40} \mathrm{Ar}^{14+}$ ion beam with the $\varnothing 20 \mathrm{~mm} \mathrm{HE}_{11}$ mode at $24 \mathrm{GHz}$, the contribution of the second frequency, i.e. $18 \mathrm{GHz}$, enhances the ion beam intensity by $25 \%$. Figure 20 shows the strong contribution of the second frequency heating, which does not only rely on plasma stability. This contribution to beam intensity enhancement probably leads to a better absorption of the $24 \mathrm{GHz}$ or stronger electron density increase.

\section{F. Magnetic field effect}

The magnetic field configuration parametrized by $B_{\text {rad, }}$, $B_{\text {inj }}, B_{\text {min }}$ and $B_{\text {ext }}$ has a significant impact on the performance of a highly charged ECR ion source for providing the electron heating and determining plasma confinement time. What is the best magnetic field configuration for the production of highly charged ion beams by ECR ion sources remains arguably a possibility for further enhancing source performance, which has been studied by many groups $[19,29,43,62,88-94]$, even though the empirical magnetic-field design criteria work well. Magnetic field studies for $18+14.5$ and $24+18 \mathrm{GHz}$ double-frequency heating were carried out with SECRAL. Table II shows the key values of the magnetic fields $B_{\text {rad }} / B_{\text {ecr }}, B_{\text {inj }} / B_{\text {ecr }}, B_{\text {min }} / B_{\text {rad }}, B_{\text {ext }} / B_{\text {rad }}$ and $B_{\text {last }} / B_{\text {ecr }}$, which demonstrate a good agreement with the well-established scaling laws by Hitz [62]. Whatever the element and charge state, the magnetic parameters used with SECRAL even under the double frequency heating, they all the time are in agreement, except however for $\mathrm{Ar}^{16+}$ where the extraction field is somehow high. The minimum value of the axial mirror magnetic field $\left(B_{\min }\right)$ has a big impact on

TABLE II. Ratios of those key magnetic field values $B_{\text {rad }} / B_{\text {ecr }}, B_{\text {inj }} / B_{\text {ecr }}, B_{\text {min }} / B_{\text {rad }}, B_{\text {ext }} / B_{\text {rad }}, B_{\text {last }} / B_{\text {ecr }}$ at $18+14.5 \mathrm{GHz}$ and $24+18 \mathrm{GHz}$ double frequency heating to achieve the best beam intensities for SECRAL.

\begin{tabular}{lcccccccccc}
\hline \hline & \multicolumn{2}{c}{$B_{\text {rad }} / B_{\text {ecr }}$} & \multicolumn{2}{c}{$B_{\text {inj }} / B_{\text {ecr }}$} & \multicolumn{2}{c}{$B_{\text {min }} / B_{\text {rad }}$} & \multicolumn{3}{c}{$B_{\text {ext }} / B_{\text {rad }}$} & \multicolumn{2}{c}{$B_{\text {last }} / B_{\text {ecr }}$} \\
\hline Ion beam & $\begin{array}{c}24+18 \\
\mathrm{GHz}\end{array}$ & $\begin{array}{c}18+14.5 \\
\mathrm{GHz}\end{array}$ & $\begin{array}{c}24+18 \\
\mathrm{GHz}\end{array}$ & $\begin{array}{c}18+14.5 \\
\mathrm{GHz}\end{array}$ & $\begin{array}{c}24+18 \\
\mathrm{GHz}\end{array}$ & $\begin{array}{c}18+14.5 \\
\mathrm{GHz}\end{array}$ & $\begin{array}{c}24+18 \\
\mathrm{GHz}\end{array}$ & $\begin{array}{c}18+14.5 \\
\mathrm{GHz}\end{array}$ & $\begin{array}{c}24+18 \\
\mathrm{GHz}\end{array}$ & $\begin{array}{c}18+14.5 \\
\mathrm{GHz}\end{array}$ \\
\hline${ }^{40} \mathrm{Ar}^{12+}$ & 1.8 & 1.8 & 3.8 & 3.4 & 0.34 & 0.39 & 0.97 & 1.06 & 1.94 \\
${ }^{40} \mathrm{Ar}^{16+}$ & 1.9 & 2.3 & 4.1 & 4.1 & 0.36 & 0.37 & 1.05 & 1.43 & 2.02 \\
${ }^{129} \mathrm{Xe}^{27}$ & 1.91 & 2.0 & 4.1 & 3.9 & 0.37 & 0.41 & 1.10 & 1.10 & 2.04 \\
${ }^{129} \mathrm{Xe}^{34}$ & 1.92 & 2.0 & 4.1 & 3.9 & 0.36 & 0.40 & 1.09 & 1.05 & 2.05 \\
${ }^{9} \mathrm{Bi}^{31+}$ & 1.84 & 1.9 & 4.0 & 3.9 & 0.38 & 0.40 & 1.08 & 1.05 & 1.97 \\
${ }^{209} \mathrm{Bi}^{36+}$ & 1.84 & 2.0 & 4.0 & 4.1 & 0.38 & 0.39 & 1.08 & 1.00 & 1.97 \\
${ }^{209} \mathrm{Bi}^{50+}$ & 1.84 & 2.0 & 4.0 & 4.1 & 0.36 & 0.41 & 1.08 & 1.05 & 1.96 \\
\hline \hline
\end{tabular}


TABLE III. The optimum $B_{\min }$ values and the corresponding beam intensities for optimizing different ion beam production at different microwave power level during SECRAL beam tests at $24+18 \mathrm{GHz}$.

\begin{tabular}{lccc}
\hline \hline Ion beam & $\mathrm{I}(\mathrm{e} \mu \mathrm{A})$ & $\mathrm{P}_{r f}(\mathrm{~kW})$ & $B_{\min }(T)$ \\
\hline${ }^{40} \mathrm{Ar}^{12+}$ & $850-1000$ & $4-5$ & 0.56 \\
& $1100-1250$ & $6-7$ & 0.55 \\
& $1250-1420$ & $8-9$ & 0.54 \\
${ }^{40} \mathrm{Ar}^{14+}$ & $360-520$ & $4-5$ & 0.56 \\
& $630-750$ & $6-7$ & 0.58 \\
& $750-846$ & $8-9$ & 0.59 \\
${ }^{129} \mathrm{Xe}^{27+}$ & $270-430$ & $3-4$ & 0.59 \\
& $480-630$ & $5-6$ & 0.58 \\
& $700-920$ & $7-9$ & 0.58 \\
${ }^{129} \mathrm{Xe}^{30+}$ & $150-190$ & $3-4$ & 0.60 \\
& $220-350$ & $7-8$ & 0.62 \\
${ }^{209} \mathrm{Bi}^{31+}$ & 242 & 2.8 & 0.60 \\
& 680 & 6.1 & 0.59 \\
\hline \hline
\end{tabular}

highly charged ion beam production of an ECR ion source because the magnetic field distribution affects the plasma confinement and the electron heating effect, which has been studied by a few groups $[19,43,62,88-94]$. Table III shows the optimum $B_{\min }$ values and the corresponding beam intensities for optimizing different ion beam production at different microwave power level during SECRAL beam tests at $24+18 \mathrm{GHz}$.

It is interesting to notice that the magnetic field distribution for SECRAL operation at $24+18 \mathrm{GHz}$ is very similar to those of VENUS and RIKEN-SCECR operating at $28+18 \mathrm{GHz}$ as presented in Table IV [19,22,65,91,9395]. Particularly, comparison of the axial mirror magnetic fields between SECRAL and VENUS for optimizing production of different highly charged ion beams such as $\mathrm{Ar}^{16+}, \mathrm{Xe}^{27+}, \mathrm{Bi}^{31+}, \mathrm{U}^{34+}$ and $\mathrm{Bi}^{50+}$ could be interesting and the axial fields approximately are $B_{\text {inj }} \sim 3.5 \mathrm{~T}, B_{\min } \sim$ $0.45-0.60 \mathrm{~T}$ and $B_{\text {ext }} \sim 1.7-2.2 \mathrm{~T}$ for SECRAL and VENUS. The axial magnetic field profiles for SECRAL and VENUS achieving the maximum ${ }^{209} \mathrm{Bi}^{30+}$ intensity is shown in Fig. 21 [19,65,95], and the new axial magnetic field profile after a few technical modifications for VENUS is also shown in Fig. 21 for comparison [65]. Table IV and

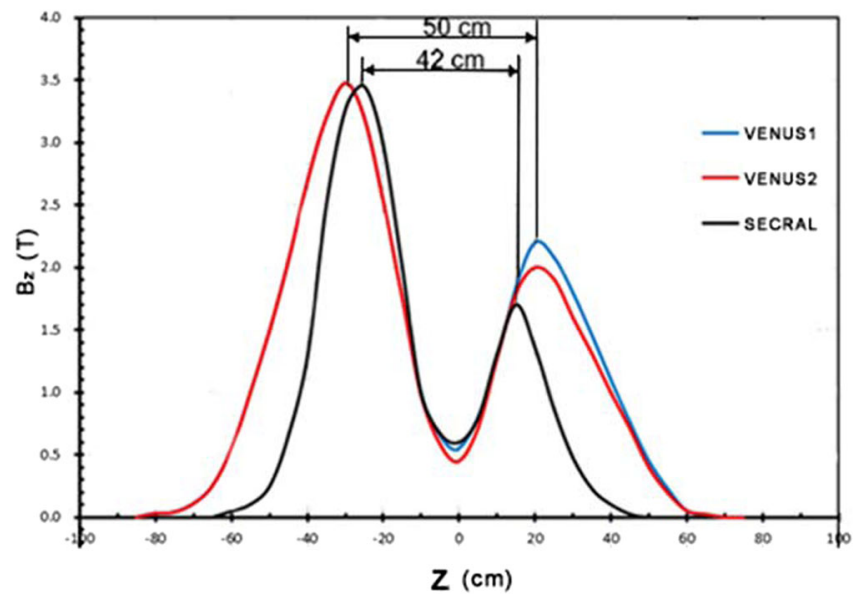

FIG. 21. Comparison of the axial magnetic field distribution between SECRAL and VENUS. (The blue line VENUS1 and the dark line SECRAL are the magnetic field distribution for optimizing high intensity ${ }^{209} \mathrm{Bi}^{30+}$ beam respectively. The red line VENUS2 is the new field distribution for VENUS after modifications.)

Fig. 21 demonstrate that the axial injection peak field $B_{\text {inj }}$ for SECRAL and VENUS is almost the same, and the magnetic field gradient $\nabla B$ and the minimum-B field $B_{\text {min }}$ are quite similar or no significant difference. But the key differences of the field distributions for the two sources are located at the mirror space, the extraction peak field $B_{\text {ext }}$ and the sextupole field at the plasma chamber inner wall $B_{\text {rad. }}$. The $B_{\text {ext }}$ for SECRAL is much lower than that of VENUS because the sextupole field $B_{\text {rad }}$ at the plasma chamber wall for SECRAL is lower than that of VENUS, in which VENUS operated previously at higher $B_{\text {ext }}$ is likely due to poor electrode cooling [65]. The extraction field peak and correspondingly the plasma electrode for SECRAL are about $3 \mathrm{~cm}$ closer to the ECR zone compared to that of VENUS. The new axial magnetic field profile of VENUS (the red line in Fig. 21) with lower $B_{\min }$, lower $B_{\text {ext }}$, but higher $B_{\text {rad }}$, is likely due to higher microwave power operation $(10 \mathrm{~kW})$ and lower bremsstrahlung radiation [63-65].

The question arises why the optimum magnetic fields are so close for achieving the best intensities of those different ion beams such as $\mathrm{Ar}^{16+}, \mathrm{Xe}^{30+}, \mathrm{Xe}^{34+}, \mathrm{Bi}^{36+}$ and $\mathrm{Bi}^{50+}$ ? The reason could be the value of the key parameters $n_{e} \tau_{i}$

TABLE IV. Comparison of the optimized magnetic fields among SECRAL, VENUS and RIKEN-SCECR.

\begin{tabular}{lccc}
\hline \hline & $28(24)+18 \mathrm{GHz} B_{\text {rad }}, B_{\text {inj }}$, & $18+14.5 \mathrm{GHz} B_{\text {rad }}, B_{\text {inj }}$, & \\
ECR ion source & $B_{\text {min }}, B_{\text {ext }}(\mathrm{T})$ & $B_{\text {min }}, B_{\text {ext }}(\mathrm{T})$ & Ion beams to optimize \\
\hline SECRAL & $1.63,3.43,0.51-0.60,1.71$ & $1.28,2.56,0.49-0.55,1.28$ & $\mathrm{Ar}^{16+}, \mathrm{Xe}^{27+}, \mathrm{Xe}^{34+} \mathrm{Bi}^{30+}, \mathrm{Bi}^{36+}, \mathrm{Bi}^{50+}$ \\
VENUS(1) & $2.0,3.5,0.55-0.6,2.0-2.2$ & $1.28,2.56,0.51,1.47$ & $\mathrm{Xe}^{27+}, \mathrm{Xe}^{28+}, \mathrm{Bi}^{30+}$ \\
VENUS(2) & $2.2,3.5,0.45,2.0$ & & $\mathrm{O}^{7+}, \mathrm{Ar}^{14+}, \mathrm{Ar}^{16+}$ \\
RIKEN SCECR & $1.88,3.1,0.65,1.78$ & $1.21,2.30,0.51,1.21$ & ${ }^{238} \mathrm{U}^{35+}$ \\
\hline \hline
\end{tabular}


and $T_{e}$ related to the confinement and electron heating are quite close or at the similar level if we look at Golovanivsky's diagram of the $\left(n_{e} \cdot \tau_{i}\right) T e$ criteria $[82,96]$. Moreover, differences of the optimum values $B_{\min }$ for those different ion beams and even for the different heating frequencies are minor or of no significant difference ranging from $0.45-0.65 \mathrm{~T}$ only, which may be due to the reason that production of those different highly charged ions requests the similar level of the hot electron energy $T_{e}$, and possibly $T_{e}$ could be determined by $B_{\min }$, and $T_{e}$ may be independent on the microwave heating frequency. This explanation is consistent with the recent bremsstrahlung measurements at VENUS demonstrating the spectra temperature $T_{s}$ is linearly dependent on $B_{\min }$ and independent on the microwave frequency [64].

Effects of the magnetic field configuration on the ECR electron heating and plasma confinement are very much sophisticated and remain arguable. Gammino [43] and Leitner [91] point out in terms of bremsstrahlung spectrum measurements at VENUS that the magnetic field gradient near the resonance zone $\nabla B$ plays a key role for the hot electron production and the source performance, which is also related to the axial minimum field $B_{\min }$. A gentler magnetic field gradient at the resonant zone will result in a more efficient heating process and will lead to the generation of a hot electron tail in the electron energy distribution, and this high energy tail is strongly affected by the ratio of $B_{\min } / B_{\mathrm{ECR}}$ and by the heating frequency [91], while the sextupole field under the high-B mode requirements and the improvement of the electron confinement due to the suppression of any MHD instability plays a major role in determining the plasma dynamics, and the sextupole field has a limited influence on the electron energy distribution function, but it affects the electron density [43]. Nakagawa has studied a lot on the magnetic field effect on performance of an ECR ion source [88-90, 94]. Nakagawa's studies stress that not only $B_{\mathrm{inj}}, B_{\min } B_{\mathrm{rad}}$ and $\nabla B$, but also $B_{\text {ext }}$, are quite essential to the source performance on highly charged ion beam production, and optimum $B_{\min }$ to maximize the beam intensity is dependent on the gas pressure and biased disk voltage [94]. Benitez [64] reported recently that bremsstrahlung spectrum measurements at VENUS have demonstrated the spectra temperature $T s$ is independent on the field gradient $\nabla B$ and the heating frequency, but $T s$ is dependent on $B_{\min }$ [64]. However, $B_{\text {inj }}, B_{\text {min }}, B_{\text {ext }}$ and the magnetic field gradient $\nabla B$ are always quite difficult to be decoupled, and it is still an open question which parameter is the most dominant one and how these magnetic-field parameters impact on those key ECR-plasma parameters $n_{e}, \tau_{i}, \tau_{e}$ and $T_{e}$, and then correspondingly how to impact on the performance of highly charged ECR source. These key issues are essential to intense beam production of very high charge state ions such as $\mathrm{Xe}^{48+}, \mathrm{Bi}^{60+}$ and $\mathrm{U}^{60+}$, and also very crucial to the design of the fourth generation ECR ion source.

\section{G. Summary of the update performance of SECRAL}

The present performance of SECRAL on the production of highly charged ion beams has been enhanced drastically since its first beam produced in 2005. Such enhancement is the accumulation of continuous exploration and component modifications as described previously. Particularly, efficient cooling of the injection system (biased disk, waveguide, etc.) and new $24 \mathrm{GHz}$ microwave launching enabled SECRAL to operate stably at total microwave power up to $7-9 \mathrm{~kW}$ of $24+18 \mathrm{GHz}$. The great performance improvements lead to many intensity records of highly charged heavy ion beams from an ECR in source. Table V summarizes all beam intensity records presently produced by SECRAL in comparison to those produced by VENUS after modifications of the new microwave coupling and raising the microwave power up to $10 \mathrm{~kW}$ and the extraction voltage up to $28 \mathrm{kV}[13,65,75-76]$.

Figures 22 illustrates beam intensity evolution of ${ }^{209} \mathrm{Bi}^{31+}$ and ${ }^{129} \mathrm{Xe}^{30+}$ with different technical developments from year 2006 to year $2015 .{ }^{209} \mathrm{Bi}^{31+}$ intensity has been increased by a factor of 10 , while ${ }^{129} \mathrm{Xe}^{30+}$ beam intensity has been increased by a factor of 3 .

On the other hand, one has to keep in mind that the frequency gap between 24 and $18 \mathrm{GHz}$ for the doublefrequency heating is smaller than that with $28+18 \mathrm{GHz}$, which may be beneficial to SECRAL operations. However, source tuning indicates that the SECRAL performance

TABLE V. The record beam intensities presently produced by SECRAL and comparison to those produced by VENUS*.

\begin{tabular}{|c|c|c|c|}
\hline Ion beam & $\begin{array}{c}\text { SECRAL I }(\mathrm{e} \mu \mathrm{A}) \\
18+14.5 \mathrm{GHz} \\
2-3.2 \mathrm{~kW}\end{array}$ & $\begin{array}{c}\text { SECRAL I }(\mathrm{e} \mu \mathrm{A}) \\
24+18 \mathrm{GHz} \\
4-9 \mathrm{~kW}\end{array}$ & $\begin{array}{c}\text { VENUS I }(\mathrm{e} \mu \mathrm{A}) \\
28+18 \mathrm{GHz} \\
4-9 \mathrm{~kW}\end{array}$ \\
\hline $\mathrm{Ar}^{12+}$ & 510 & 1420 & 1060 \\
\hline $\mathrm{Ar}^{14+}$ & 270 & 846 & 840 \\
\hline $\mathrm{Ar}^{16+}$ & 73 & 350 & 523 \\
\hline $\mathrm{Ar}^{17+}$ & 8.5 & 50 & 115 \\
\hline $\mathrm{Xe}^{20+}$ & 505 & & \\
\hline $\mathrm{Xe}^{26+}$ & 410 & 1100 & \\
\hline $\mathrm{Xe}^{27+}$ & 306 & 920 & \\
\hline $\mathrm{Xe}^{30+}$ & 101 & 322 & 211 \\
\hline $\mathrm{Xe}^{34+}$ & 21 & 90 & \\
\hline $\mathrm{Xe}^{42+}$ & 1.5 & 10 & 1 \\
\hline $\mathrm{Bi}^{30+}$ & 191 & 710 & \\
\hline $\mathrm{Bi}^{31+}$ & 150 & 680 & 300 \\
\hline $\mathrm{Bi}^{41+}$ & 22 & 100 & \\
\hline $\mathrm{Bi}^{45+}$ & 15 & 49 & \\
\hline $\mathrm{Bi}^{50+}$ & 1.5 & 10 & 5.3 \\
\hline $\mathrm{Bi}^{55+}$ & & 1.5 & \\
\hline $\mathrm{U}^{32+}$ & & 200 & 450 \\
\hline $\mathrm{U}^{33+}$ & & 202 & 400 \\
\hline
\end{tabular}

*Argon beam intensities produced by VENUS were published in 2016 [65] and the other beams produced by VENUS were published before 2013 [13,75-76]. 

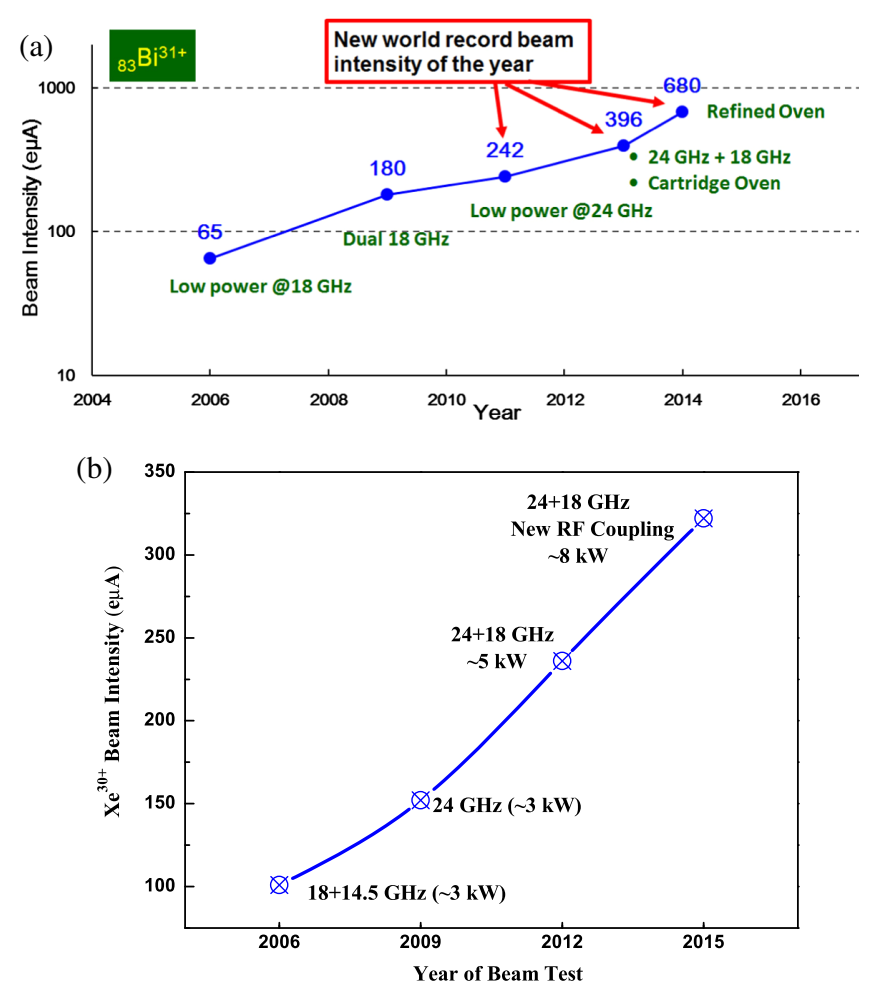

FIG. 22. ${ }^{209} \mathrm{Bi}^{31+}$ (a) and ${ }^{129} \mathrm{Xe}^{30+}$ (b) beam intensity evolution with different technical developments from the year 2006 to 2015 .

would be further improved if the magnetic fields both for the sextupole and the axial mirror fields could reach higher values.

\section{BEAM QUALITY AND LONG-TERM OPERATIONS}

\section{A. Beam emittance}

Beam emittance $\varepsilon$ is a key issue for an ECR ion source, particularly for application in accelerator. Accelerator physicists always require higher beam brightness defined by the square of the beam current $I$ over the emittance, i.e. brightness $=I^{2} / \varepsilon$, thus for the same beam current, the lower the emittance is the higher the brightness. Generally speaking, the ion beam intensities of the third generation ECR ion sources have been enhanced by a factor of 2-10 over the second generation ECR sources, achieved by increasing the magnetic fields and microwave power by a factor of 1.5-2. One of the main concerns is the beam quality for the third generation ECR ion source when microwave frequency, microwave power and magnetic fields are strongly increased. A beam emittance study has been conducted with SECRAL at both 18 and $24 \mathrm{GHz}$ by an Allison emittance scanner located just behind the focal point of the analyzing magnet. The challenge to a good beam emittance study of an ECR source is that it is sensitive to the source tuning, plasma
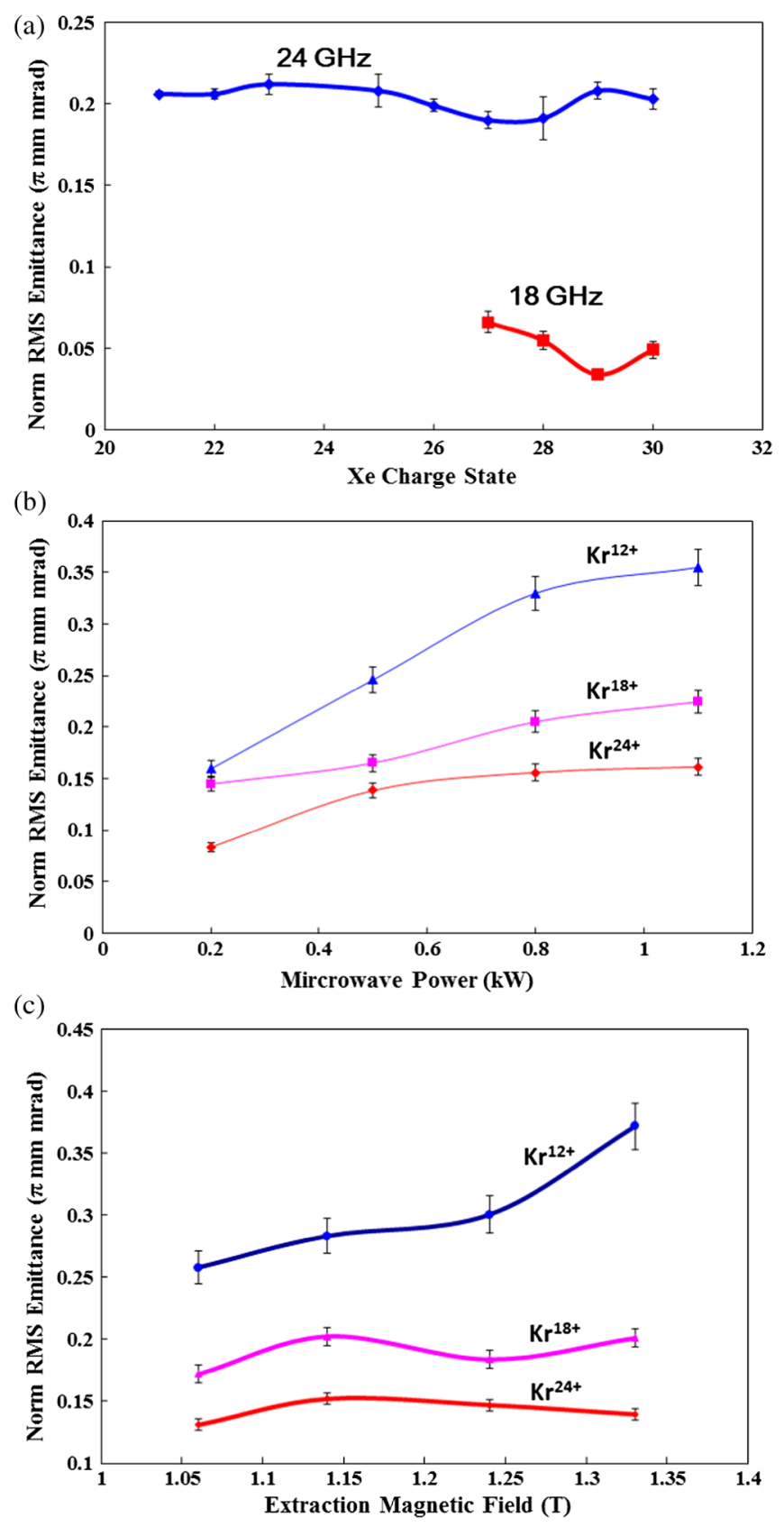

FIG. 23. SECRAL beam emittance study. (a) Xenon beam emittance measured at low microwave power of 24 and $18 \mathrm{GHz}$. (b) Dependences of normalized rms emittance on $18 \mathrm{GHz}$ microwave power measured at SECRAL. (c) Dependences of normalized rms emittance on the extraction peak field at $18 \mathrm{GHz}$ SECRAL.

condition and quality of the beam transport line. Thus at roughly the same conditions the study can result in relative and statistical comparison of beam emittance.

Square root normalized rms emittance $\varepsilon_{\mathrm{sr}}=$ $\left(\varepsilon_{x n-\mathrm{rms}}^{2}+\varepsilon_{y n-\mathrm{rms}}^{2}\right)^{1 / 2}$ is typically a good quality depiction of an ion beam. Figure 23(a) shows the measurements of normalized rms emittance in the horizontal direction for high charge state xenon ion beams produced with SECRAL 

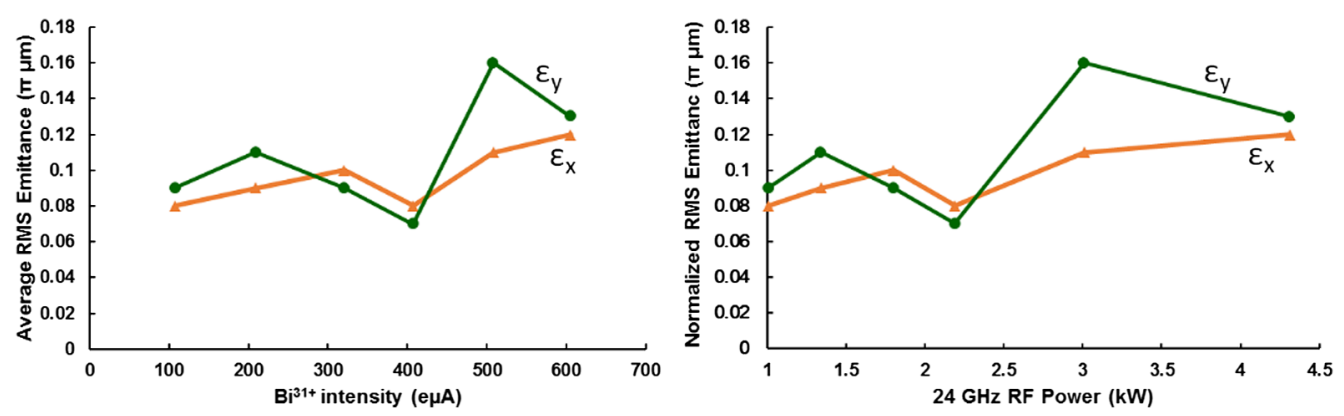

FIG. 24. Dependences of normalized rms emittance on the beam ${ }^{209} \mathrm{Bi}^{31+}$ intensity and the $24 \mathrm{GHz}$ microwave power at SECRAL.

at low microwave power of 24 and $18 \mathrm{GHz}$ (both less than $1 \mathrm{~kW}$ ) at $15-20 \mathrm{kV}$ extraction voltage. It indicates that emittance at $24 \mathrm{GHz}$ operation, with low beam intensity and low microwave power, is larger than that at $18 \mathrm{GHz}$. Dependences of the normalized rms emittance on the operating $18 \mathrm{GHz}$ microwave power and the extraction peak field for the ion beams ${ }^{78} \mathrm{Kr}^{24+},{ }^{78} \mathrm{Kr}^{18+}$ and ${ }^{78} \mathrm{Kr}^{12+}$ beams were measured at SECRAL, as shown in Figs. 23(b) and 23(c), respectively. Figure 23(b) indicates beam emittance could increase slightly with the wave power and beam intensity although the measurements were conducted at lower power and low beam intensity. Figure 23(c) shows that increasing the extraction peak field may raise the beam emittance slightly and emittance variations of different charge state could be different. The emittance measurement errors shown in Fig. 23 are errors of mean square root calculated from many time measurements. Emittance studies with SECRAL in Fig. 23 were conducted with low beam current less than $100 \mathrm{e} \mu \mathrm{A}$ and low wave power less than $1.5 \mathrm{~kW}$. Figure 24 illustrates dependence of normalized rms emittance on the beam intensity of ${ }^{209} \mathrm{Bi}^{31+}$ from $100 \mathrm{e} \mu \mathrm{A}$ to $600 \mathrm{e} \mu \mathrm{A}$ versus $24 \mathrm{GHz}$ power from 1 to $4.5 \mathrm{~kW}$ [35]. Each beam emittance measurement in Fig. 24 was conducted by optimizing all other source parameters to reach the highest beam intensity of ${ }^{209} \mathrm{Bi}^{31+}$ at a fixed $24 \mathrm{GHz}$ microwave power. The measurements shown in Fig. 24 indicate that the emittance of high charge state ion beam may increase with beam intensity and microwave power slightly, but even up to a few hundreds of $\mathrm{e} \mu \mathrm{A}$ and a few kilowatts of microwave power, there is no significant increase of beam emittance.

Comparing with data obtained at $18 \mathrm{GHz}$ in Fig. 23, the beam emittance shown in Fig. 24 was measured when microwave frequency, power level, magnetic fields and beam intensity were strongly increased. Figure 25 shows beam emittance phase-space patterns and beam images for the ion beam ${ }^{209} \mathrm{Bi}^{31+}$ at $115 \mathrm{e} \mu \mathrm{A}$ with $1.0 \mathrm{~kW}$ of power at $24 \mathrm{GHz}$ and $330 \mathrm{e} \mu \mathrm{A}$ with $3.4 \mathrm{~kW}$ of $24 \mathrm{GHz}$ power, respectively. It is clearly demonstrated that the beam distribution in phase space is very much distorted, which could be caused by space charge effect, transversal coupling due to the solenoid lens, aberrations from the solenoid lens and the analyzing magnet.
However, the projection emittance shown in Fig. 25 for $330 \mathrm{e} \mu \mathrm{A}$ of ${ }^{209} \mathrm{Bi}^{31+}$ produced with $3.4 \mathrm{~kW}$ of $24 \mathrm{GHz}$ power is quite large, i.e. $200-350 \pi \mathrm{mm} \mathrm{mrad}$ in the horizontal direction and $350-450 \pi \mathrm{mm}$ mrad in the vertical direction with $90 \%-95 \%$ of the beam current. This horizontal emittance value is almost the same as that obtained with VENUS for $365 \mathrm{e} \mu \mathrm{A}$ of ${ }^{238} \mathrm{U}^{33+}$ produced with $6 \mathrm{~kW}$ of $28 \mathrm{GHz}$ wave power [97], but the vertical emittance for SECRAL is larger than that of VENUS [97].

A beam quality study has demonstrated that beam emittance from SECRAL, operated at $24 \mathrm{GHz}$ at high microwave power and high magnetic fields, is at a similar level as that of $18 \mathrm{GHz}$. Generally speaking, the normalized-rms emittance is around $0.05-0.2 \pi \mathrm{mm} \mathrm{mrad}$ or slightly higher, depending upon the source tuning, the plasma conditions and the solenoid lens setting.

Beam emittance of an ECR ion source operating at higher microwave frequency and power, and higher magnetic fields, could be slightly higher but not significantly than at lower microwave frequency and power, and lower magnetic fields. The normalized-rms emittances measured with SECRAL at both 18 and $24 \mathrm{GHz}$ operations are

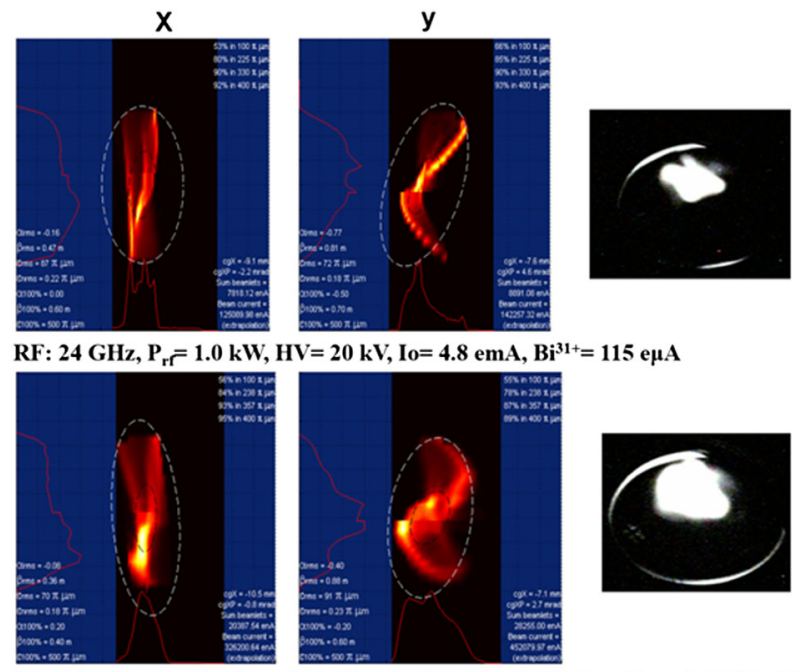

RF: $24 \mathrm{GHz}+18 \mathrm{GHz}, \mathrm{P}_{\mathrm{r}}=3.4 \mathrm{~kW}+0.3 \mathrm{~kW}, \mathrm{HV}=23 \mathrm{kV}, \mathrm{Io}=10 \mathrm{emA}, \mathrm{Bi}^{31+}=330 \mathrm{e} \mu \mathrm{A}$

FIG. 25. Beam emittance phase-space patterns and beam images for the beam ${ }^{209} \mathrm{Bi}^{31+}$ at different conditions for SECRAL operating $24 \mathrm{GHz}$. 
roughly the same as those measured with VENUS and RIKEN-SCECR [97-100].

\section{B. Beam stability}

Long-term beam stability is one of the most important qualities of an ion source. At low beam intensity, i.e. below $200 \mathrm{e} \mu \mathrm{A}$, and below $2 \mathrm{~kW}$ of microwave power, long-term beam stability has been demonstrated by many ECR ion sources delivering beams to the heavy ion accelerators [89,101-105], but not yet for highly charged heavy ion beam intensity exceeding $300 \mathrm{e} \mu \mathrm{A}$ produced with wave power above $5 \mathrm{~kW}$.

The microscopic instability could be caused by kinetic plasma instabilities resulting in periodic beam intensity oscillations, which have been studied by Skalyga and Tarvainen [51,54-55,106] recently and also reported by Kitagawa [107] and Nakagawa [105].

The plasma instabilities due to electron cyclotron instabilities may arise from the strongly anisotropic distribution function of electrons in the velocity space, which fundamentally affects the plasma confinement and leads to a disruption of highly charged ion production [51,54-55]. The beam instabilities caused by the plasma instabilities could be partially mitigated by the two-frequency heating and optimized tuning of the magnetic field distribution, which were reported by many ECRIS labs [31,51,74,76,92,106-108].

Figure 26 shows suppression of beam instabilities by two-frequency heating $(28+24 \mathrm{GHz})$ and three-frequency heating $(28+24+18 \mathrm{GHz})$ conducted recently with SECRAL at $3 \mathrm{~kW} 28 \mathrm{GHz}$ microwave power for ${ }^{129} \mathrm{Xe}^{27+}$ beam intensity around $550 \mathrm{e} \mu \mathrm{A}$. Figure 26 illustrates that the role of the $18 \mathrm{GHz}$ at $200 \mathrm{~W}$ is only to stabilize the plasma during the three-frequency heating $(28+24+18 \mathrm{GHz})$; while the second frequency $24 \mathrm{GHz}$, even at $200 \mathrm{~W}$, not only contributes to the beam intensity enhancement, but also to the suppression of the plasma instabilities. Nevertheless, contribution of $24 \mathrm{GHz}$ frequency to suppress the plasma instabilities is less efficient than that of $18 \mathrm{GHz}$ during the three-frequency heating $(28+24+18 \mathrm{GHz})$. Experiments with SECRAL have demonstrated that suppression of the plasma instabilities may not be effective with multifrequency heating if frequency gap is not large enough. $(28+18 \mathrm{GHz})$, $(24+18 \mathrm{GHz})$ and $(28+24+18 \mathrm{GHz})$ could be a good option respectively if only considering suppression of the plasma instabilities.

The macroscopic instability could result from outgassing and/or discharge. Such macroscopic instability could be eliminated or mitigated with long time conditioning at high microwave power. Figure 27(a) shows beam intensity instability of ${ }^{129} \mathrm{Xe}^{27+}$ at $435 \mathrm{e} \mu \mathrm{A}$ when SECRAL was tested at single frequency heating of $24 \mathrm{GHz}$ at $3.5 \mathrm{~kW}$ without a long-term conditioning and optimized tuning. After long time conditioning at total microwave power about $4 \mathrm{~kW}$, fine-tuning of the magnetic field distribution and two-frequency heating with $24+18 \mathrm{GHz}$, even higher charge state beam at high beam intensity could become quite stable as shown in Fig. 27(b) which shows the beam stability of ${ }^{129} \mathrm{Xe}^{30+}$ at $235 \mathrm{e} \mu \mathrm{A}$ achieved by $24+18 \mathrm{GHz}$ at $4.3 \mathrm{~kW}+1.3 \mathrm{~kW}$ microwave power.

Figure 27(c) demonstrates beam intensity stability of ${ }^{209} \mathrm{Bi}^{31+}$ at $330 \mathrm{e} \mu \mathrm{A}$ tested continuously during 2.5 hours by $24+18 \mathrm{GHz}$ two-frequency heating at $3.4 \mathrm{~kW}+$ $0.3 \mathrm{~kW}$ microwave power [34], from which beam intensity oscillation at small scale magnitude can be observed.

Long-term stability of ECR source beam intensity is extremely important for accelerator operation. Mechanism of beam intensity instabilities caused by the plasma instabilities or other reasons should be studied in more detail through experiments and theoretical simulations. Long-term stability during days even weeks with SECRAL at high beam intensity level above $300 \mathrm{e} \mu \mathrm{A}$ and at high microwave power level of $5 \mathrm{~kW}$ still needs to be further verified.

\section{SECRAL operations enhancing capabilities of the HIRFL accelerator complex}

The HIRFL accelerator complex is comprised of an injector cyclotron sector focus cyclotron (SFC), a main cyclotron separated sector cyclotron (SSC) and two cooling

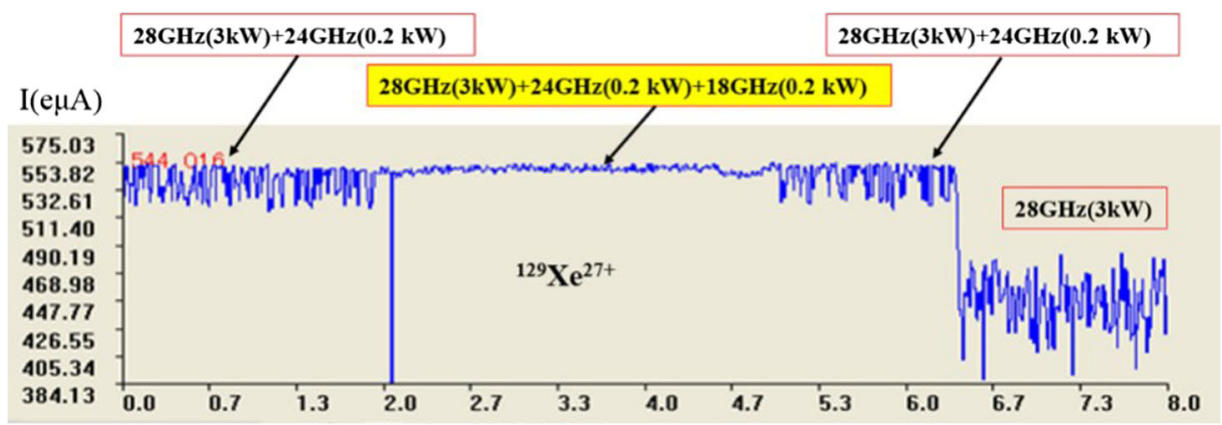

FIG. 26. Suppression effect of beam instabilities by two-frequency heating $(28+24 \mathrm{GHz})$ and three-frequency heating $(28+24+18 \mathrm{GHz})$. 

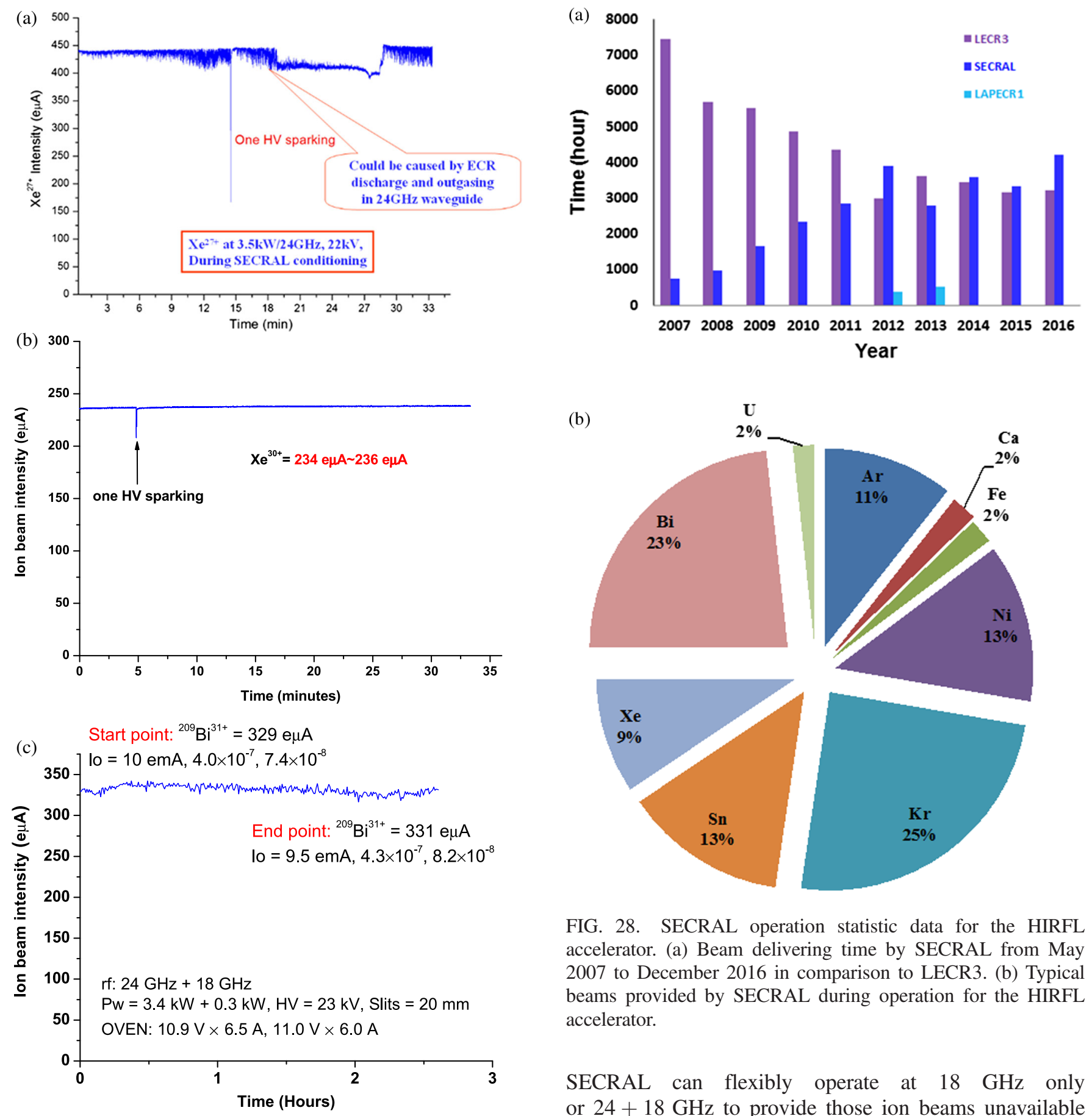

(b)

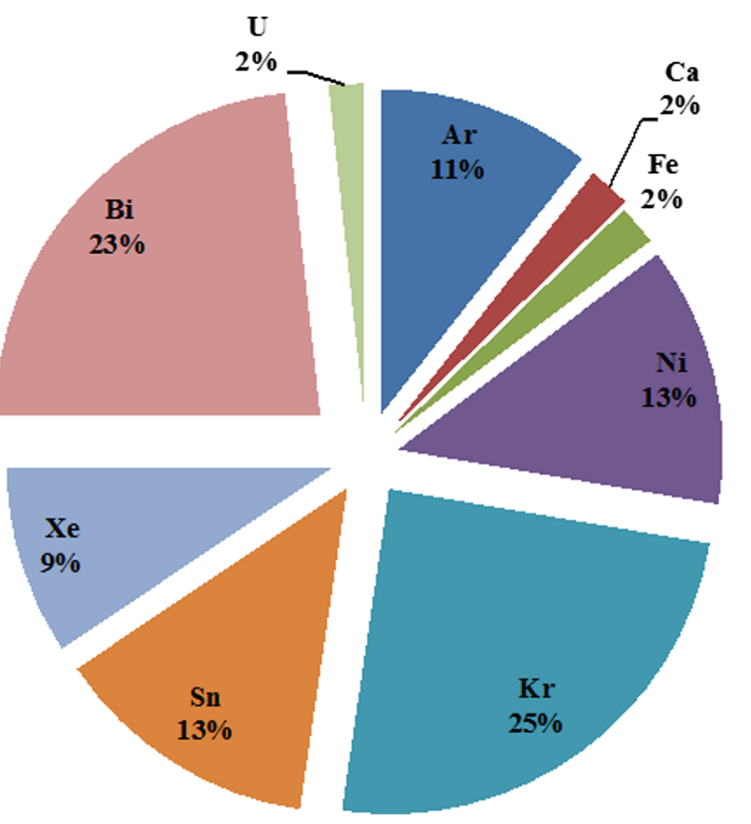

FIG. 28. SECRAL operation statistic data for the HIRFL accelerator. (a) Beam delivering time by SECRAL from May 2007 to December 2016 in comparison to LECR3. (b) Typical beams provided by SECRAL during operation for the HIRFL accelerator.

FIG. 27. SECRAL beam stability study. (a) Beam intensity instability of ${ }^{129} \mathrm{Xe}^{27+}$ at $435 \mathrm{e} \mu \mathrm{A}$ when SECRAL was tested with single frequency $24 \mathrm{GHz}$ heating at $3.5 \mathrm{~kW}$ power. (b) ${ }^{129} \mathrm{Xe}^{30+}$ beam intensity stability at $235 \mathrm{e} \mu \mathrm{A}$ with $24+18 \mathrm{GHz}$. (c) ${ }^{209} \mathrm{Bi}^{31+}$ beam intensity stability at $330 \mathrm{e} \mu \mathrm{A}$ testing continuously during 2.5 hours.

storage rings (CSR) [24]. SECRAL, used as an external ion source, has been delivering highly charged heavy ion beams to the injector SFC cyclotron since May 2007 [30]. Depending upon the required ion beam and intensity,

SECRAL can flexibly operate at $18 \mathrm{GHz}$ only or $24+18 \mathrm{GHz}$ to provide those ion beams unavailable from the room temperature ECR sources LECR2\&3 [25]. Figure 28(a) shows the beam delivery by SECRAL from May 2007 to December 2016, starting with very limited time but increasing yearly to overtake the room temperature source LECR3 in a few years. SECRAL's heavy ion beam delivery accounts for more than 3500 annual hours during 2014-2016. The total beam delivery from SECRAL to the HIRFL accelerator so far is more than 28,000 hours by June 2017. The typical ion-beam percentage delivered are graphically shown in Fig. 28(b). SFC is a small cyclotron with energy constant $\mathrm{K}=69$ and its capability has been greatly enhanced with ECR ion sources, as shown in 

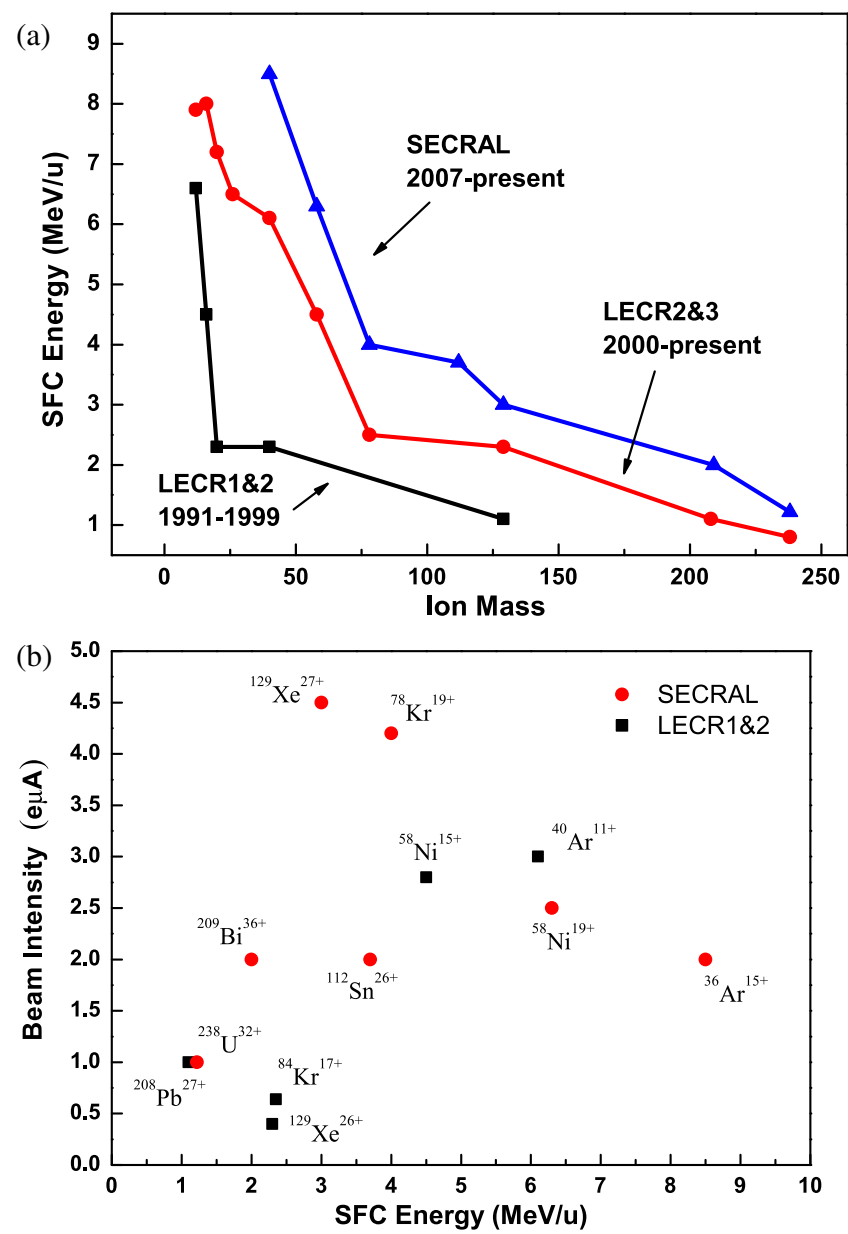

FIG. 29. Enhancement of SFC cyclotron beam energy and beam intensity due to SECRAL operation. (a) SFC beam energy improvement by SECRAL compared with the normal conducting ECR ion sources LECR0\&1 and LECR2\&3. (b) Enhancement of SFC beam intensity and energy by SECRAL compared with the normal conducting ECR ion sources LECR2\&3.

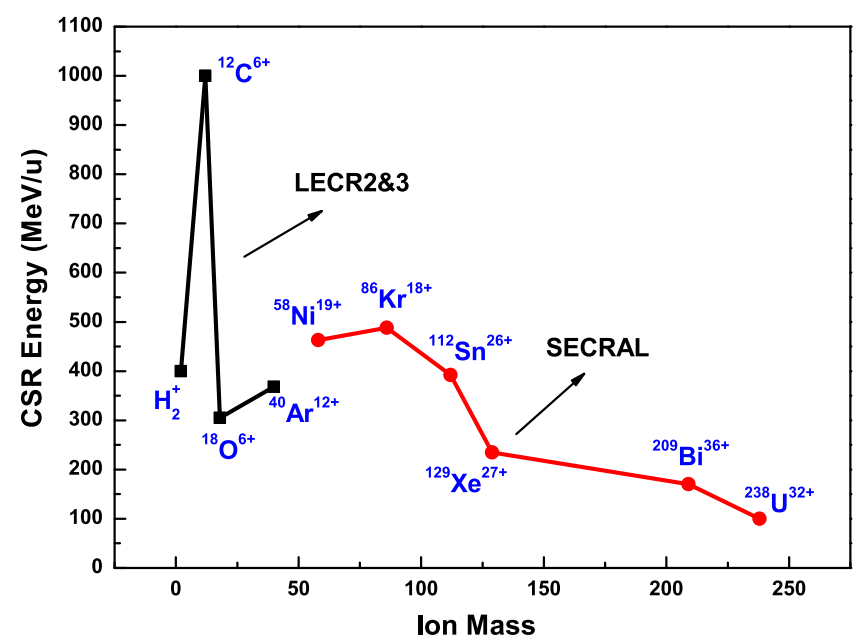

FIG. 30. CSR performance enhancement by SECRAL compared with the normal conducting ECR ion sources LECR2\&3.
Fig. 29, especially with the beam delivery from SECRAL. For example, xenon beam intensities delivered by SFC and SSC were enhanced by a factor 10 and 50 respectively thanks to SECRAL. The cooling storage ring CSR of HIRFL is capable of routinely accelerating the very heavy ions, such as tin, xenon, bismuth and uranium, to hundreds of MeV/n, as shown in Fig. 30. However, it is only possible with the energy and beam intensities delivered by the combination of the SECRAL and the SFC, fitting the injection requirements of the CSR. The enhanced capability of the HIRFL accelerator complex leads new research opportunities, shown in Fig. 31 for instance, the first precise mass measurements of more than 35 short-lived nuclides were conducted with CSR by using primary beams ${ }^{112} \mathrm{Sn}^{26+},{ }^{58} \mathrm{Ni}^{19+}$ and ${ }^{78} \mathrm{Kr}^{19+}$ delivered by SECRAL [36].

\section{UPGRADE AND FUTURE DEVELOPMENT}

A new superconducting ECR ion source, SECRAL-II, has been built for a heavy ion linac injector for the SSC cyclotron at the HIRFL [77]. SECRAL-II is almost a duplicate of SECRAL except for the cryogenic system and a slightly higher radial field and a larger plasma chamber for operation at $28 \mathrm{GHz}$. The cryogenic system of SECRAL-II was designed to be operated with 5 GM cryocoolers that are capable of providing a dynamic cooling capacity of more than $5 \mathrm{~W}$ to the $4.2 \mathrm{~K}$ reservoir to mitigate the dynamic heat load due to the strong bremsstrahlung radiation. SECRAL-II is designed to be operated at maximum frequency of $28 \mathrm{GHz}$. The SECRAL-II superconducting magnet assembly, Sol-In-Sext configuration, shown in Fig. 32, was fabricated by WST in China and finally reached $100 \%$ designed fields [77]. This new source SECRAL-II is presently under commissioning with quite promising test results, such as ${ }^{16} \mathrm{O}^{6+} 6.5 \mathrm{~mA}$ produced by $5 \mathrm{~kW} 28 \mathrm{GHz}$ microwave power [109].

The third generation of ECR ion source, like SECRAL, VENUS, RIKEN-SCECR and SuSI, has achieved remarkable advancement in the production of intense highly charged ion beams and efforts on further source performance are continuing.

However the beam intensity requirements of the very heavy ions, like lead and uranium, of future heavy ion accelerators are beyond the capability of the third generation ECR ion sources and demand the development of the next generation of ECR ion source [67,110]. To meet the demands, based on the scaling laws and what have been achieved by the third generation sources, the next generation one should operate at microwave frequency in the range of 40-60 GHz, even higher, hoping a factor of 2-5 gain in beam intensity. Such an increase implies the production of about $1.5 \mathrm{emA}$ of ${ }^{238} \mathrm{U}^{33+}, 400 \mathrm{e} \mu \mathrm{A}$ of ${ }^{238} \mathrm{U}^{40+}, 200 \mathrm{e} \mu \mathrm{A}$ of ${ }^{238} \mathrm{U}^{46+}$ and $50 \mathrm{e} \mu \mathrm{A}$ of ${ }^{238} \mathrm{U}^{50+}$ by the next generation ECR ion sources [67]. 


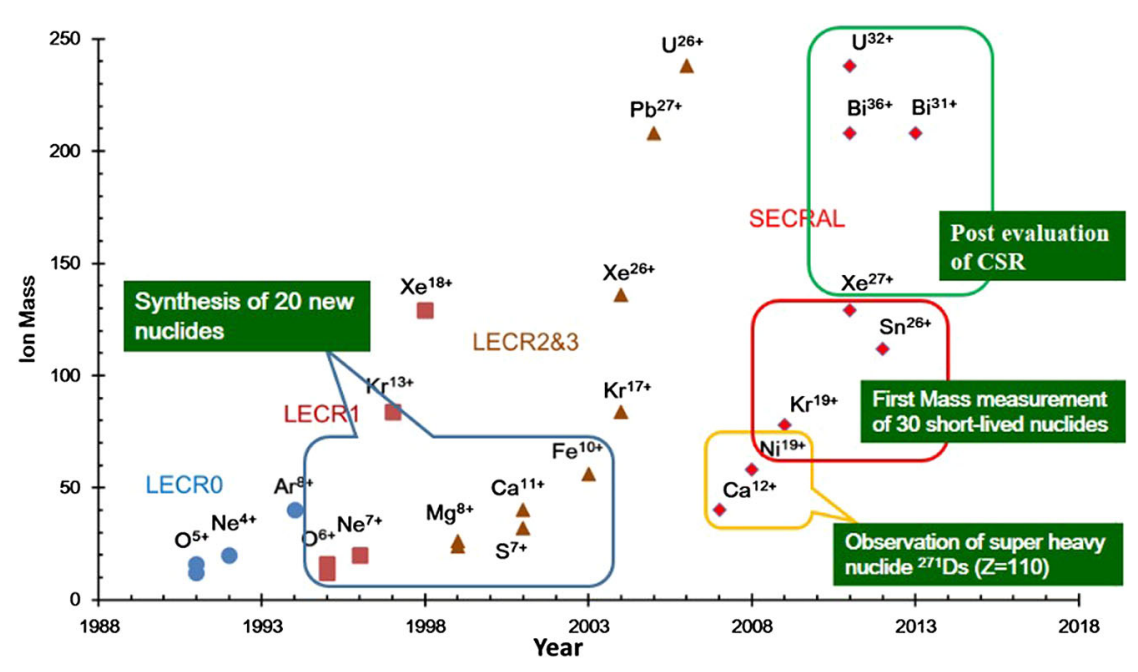

FIG. 31. Contributions of SECRAL and the normal conducting ECRIS at IMP to physics research based on the HIRFL accelerator.

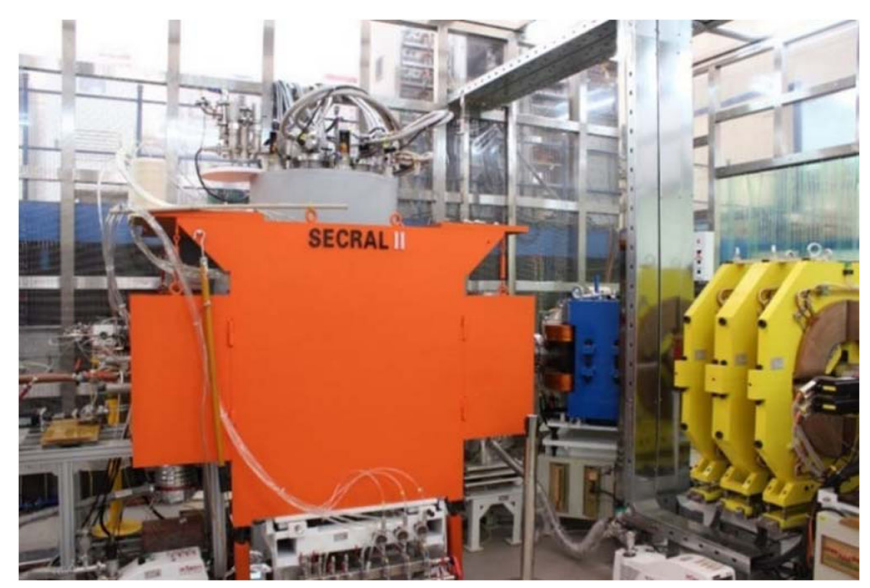

FIG. 32. The SECRAL-II ECR ion source at beam commissioning.

However, there are many challenges to overcome for the development of the next generation [67]. The prerequisite is to successfully construct a superconducting magnet that can produce peak axial mirror fields of $B_{\text {inj }}=6-8 \mathrm{~T}$ and radial field $\mathrm{B}_{\mathrm{rad}}=3-4 \mathrm{~T}$ at the chamber wall to confine a higher density and hotter ECR plasma. In addition, cryogenic system, beam extraction, quality and transport and high power $40-60 \mathrm{GHz}$ microwave coupling would be other key issues, which need carefully addressed with substantial R\&D efforts.

\section{SUMMARY AND CONCLUSION}

SECRAL is a superconducting-NbTi-magnet-based third generation ECR ion source for the production of intense multiply and highly charged ion beams. SECRAL is the first ECR ion source built with a novel magnet structure, which results in the smallest superconducting magnet for an ECR ion source, for operations at $24 \mathrm{GHz}$ microwave frequency. SECRAL combines a high strength minimum-B field generated by the novel magnet with high power of 18 $24 \mathrm{GHz}$ microwaves to energize the ECR plasma to produce the intense multiply and highly charged ion beams. During the decade development, from initial commissioning at $18 \mathrm{GHz}$ to high power $24 \mathrm{GHz}$ regular operation, beam intensities have been increased by a factor of 3 to 10 for those typical highly charged ion beams such as ${ }^{129} \mathrm{Xe}^{30+}$ and ${ }^{209} \mathrm{Bi}^{31+}$. A number of world record ECRIS $\mathrm{cW}$ beam intensities have been produced recently by SECRAL, such as $1420 \mathrm{e} \mu \mathrm{A}$ of ${ }^{40} \mathrm{Ar}^{12+}, 1100 \mathrm{e} \mu \mathrm{A}$ of ${ }^{129} \mathrm{Xe}^{26+}, 322 \mathrm{e} \mu \mathrm{A}$ of ${ }^{129} \mathrm{Xe}^{30+}, 680 \mathrm{e} \mu \mathrm{A}$ of ${ }^{209} \mathrm{Bi}^{31+}$, and $10 \mathrm{e} \mu \mathrm{A}$ of ${ }^{209} \mathrm{Bi}^{50+}$. This remarkable performance has been achieved due to several technical advancements and innovations like the innovative magnet structure and the effective double frequency heating $(24+18 \mathrm{GHz})$, especially with the recent new microwave coupling scheme for high microwave power operation at $24 \mathrm{GHz}$ plus $18 \mathrm{GHz}$. The achievement of a good number of ECRIS record intense beams and more than 28,000 hours of beam delivery to the HIRFL accelerator facility have demonstrated that SECRAL is one of the world's best-performing third generation ECR ion sources. With the greater variety of ion beams from SECRAL, the overall capability of the HIRFL accelerator complex has been dramatically enhanced with higher beam energy and intensity, which has opened up many new research opportunities at IMP. Based upon the demonstrated performance of the third generation of ECR ion source and its significant impact to heavy ion accelerators, it is reasonable to anticipate the next generation of ECR ion source will greatly advance the future heavy ion accelerator facility and physics research.

The following conclusions could be drawn from the development of SECRAL.

(1) To produce stable and intense beams of highly charged heavy ions, the third generation ECR ion source needs to operate at multifrequency heating $(24+18$ or 
$28+18 \mathrm{GHz}$ ) with total microwave power more than $5 \mathrm{~kW}$ and effective cooling to all components inside the plasma chamber.

(2) The new microwave coupling through a smaller circular waveguide of $\varnothing 20 \mathrm{~mm}$, instead of the original $\emptyset 32 \mathrm{~mm}$ waveguide, to launch the $\mathrm{TE}_{01}$ microwaves into the plasma improves SECRAL performance significantly for the production of highly charged ion beams. This indicates that there will be an optimum for better wave coupling that will be very important for both the third generation and the next generation ECR ion source.

(3) For high power operations in the third generation ECR ion sources, optima should exist in the frequency gap of double-frequency heating and matched magnetic field configuration.

(4) The optimum magnetic fields for SECRAL to produce the highly charged ion beam typically are in the ranges of $B_{\text {rad }}=2.0 B_{\text {ecr }}, B_{\text {inj }}=4.0 B_{\text {ecr }}, B_{\text {min }}=0.35-0.40 B_{\text {rad }}$, and $B_{\text {ext }}=1.0 B_{\text {rad }}$ for operations with high power at $18-24 \mathrm{GHz}$ wave frequency; The optimum magnetic fields are very similar for achieving the best intensities of those different ion beams such as $\mathrm{Ar}^{16+}, \mathrm{Xe}^{30+}, \mathrm{Xe}^{34+}, \mathrm{Bi}^{36+}$ and $\mathrm{Bi}^{50+}$. Differences of the optimum values $B_{\min }$ for those different ion beams and even for the different heating frequencies $18-28 \mathrm{GHz}$ are minor or no significant difference ranging $0.45-0.60$ T only.

(5) SECRAL beam emittance studies have demonstrated that beam emittance of the third generation ECR ion source operated at 24-28 GHz with higher microwave power and higher magnetic fields is roughly the same compared to that at $18 \mathrm{GHz}$, i.e. no significant emittance increase for ECRIS operating at higher fields and high frequencies.

(6) Long-term operating stability of beam intensity of days and weeks at high intensity of more than $300 \mathrm{e} \mu \mathrm{A}$ and at high microwave power of $>5 \mathrm{~kW}$, still needs demonstration for the third generation ECR ion sources.

\section{ACKNOWLEDGMENTS}

This work was supported by National Key Basic Research Program of China (No. 2014CB845500), National Nature Science Foundation of China (No. 11427904, No. 10921504 and No. 11221064), and Project of Knowledge Innovation Program of Chinese Academy of Sciences. The authors are very grateful to the fruitful discussions during the development of SECRAL with C.M. Lyneis, D. Leitner of LBNL, T. Nakagawa of RIKEN, S. Gammino of LNS/INFN, K. Tinschert and P. Spaedtke of GSI and R. Pardo of ANL.

[1] R. Geller, Electron Cyclotron Resonance Ion Sources and ECRPlasma (Institute of Physics, Bristol, 1996).
[2] D. Hitz, Recent Progress in High Frequency Electron Cyclotron Resonance Ion Sources, Adv. Imaging Electron Phys. 144, 1 (2006).

[3] C. M. Lyneis, D. Leitner, D. S. Todd, G. Sabbi, S. Prestemon, S. Caspi, and P. Ferracin, Fourth generation electron cyclotron resonance ion sources (invited), Rev. Sci. Instrum. 79, 02A321 (2008).

[4] R. Geller, Electron cyclotron resonance multiply charged ion sources, IEEE Trans. Nucl. Sci. 23, 904 (1976).

[5] LHC Design Report Volume III: The LHC Injector Chain, Report No. CERN-2004-003, 2004 (unpublished).

[6] FBTR, FAIR Baseline Technical Report, 2006 (unpublished).

[7] DOE/NSF Nuclear Science Advisory Committee, Report to NSAC of the Rare-Isotope Beam Task Force, 2007 (unpublished).

[8] P. Bertrand and M. H. Moscatello, The advancement of SPIRAL2 project, in Proceedings of the 18th International Conference on Cyclotrons and Their Applications, Giardini Naxos, 2007, edited by D. Riffuggiato, p. 39.

[9] Y. Yano et al., The RIKEN RI Beam Factory Project: A status report, Nucl. Instrum. Methods Phys. Res., Sect. B 261, 1009 (2007).

[10] J. C. Yang et al., High Intensity heavy ion Accelerator Facility (HIAF) in China, Nucl. Instrum. Methods Phys. Res., Sect. B 317, 263 (2013).

[11] Y. Jongen, C. Pirart, and G. Ryckewaert, Superconducting source ECREVETTE, in Proceedings of the 4th International Workshop on ECR Ion Sources, Grenoble, edited by M. C. Boraso (1982), p. 31.

[12] Y. Jongen, C. Pirart, G. Ryckewaert, and J. Steyart, Status of the E.C.R. Heavy Ion Source and Its Interfacing with Cyclone, IEEE Trans. Nucl. Sci. 26, 3677 (1979).

[13] C. Lyneis, D. Leitner, M. Leitner, C. Taylor, and S. Abbott, The third generation superconducting $28 \mathrm{GHz}$ electron cyclotron resonance ion source VENUS (invited), Rev. Sci. Instrum. 81, 02A201 (2010).

[14] H. Beuscher, Status of the $14 \mathrm{GHz}$ Julich ECRIS, in Proceedings of the International Conference on the Physics of Multiply Charged Ions and International Workshop on ECR Ion Sources, Grenoble, 1989 [J. Phys. 50, 883 (1989).

[15] T. A. Antaya, Review of studies for the variable frequency superconducting ECR ion source project at MSU, in Proceedings of the International Conference on the Physics of Multiply Charged Ions and International Workshop on ECR Ion Sources, Grenoble, 1989 [J. Phys. C 50, 707 (1989).

[16] G. Ciavola, S. Gammino, P. Briand, G. Melin, and P. Seyfert, The SERSE project, Rev. Sci. Instrum. 65, 1057 (1994).

[17] S. Gammino, G. Ciavola, L. Celona, D. Hitz, A. Girard, and G. Melin, Operation of the SERSE superconducting electron cyclotron resonance ion source at $28 \mathrm{GHz}$, Rev. Sci. Instrum. 72, 4090 (2001).

[18] C. M. Lyneis, Z. Q. Xie, and C. E. Taylor, Development of the third generation electron cyclotron resonance ion source, Rev. Sci. Instrum. 69, 682 (1998).

[19] D. Leitner, C. M. Lyneis, T. Loew, D. S. Todd, S. Virostek, and O. Tarvainen, Status report of the $28 \mathrm{GHz}$ 
superconducting electron cyclotron resonance ion source VENUS (invited), Rev. Sci. Instrum. 77, 03 A302 (2006).

[20] P. A. Závodszky et al., Design, construction, and first commissioning results of superconducting source for ions at NSCL/MSU, Rev. Sci. Instrum. 79, $02 \mathrm{~A} 302$ (2008).

[21] G. Machicoane et al., First results at $24 \mathrm{GHz}$ with the superconducting source for ions (SuSI), in Proceedings of the 21st International Workshop on ECR Ion Sources, Nizhny Novgorod, 2014, p. 1.

[22] T. Nakagawa et al., First results from the new RIKEN superconducting electron cyclotron resonance ion source (invited), Rev. Sci. Instrum. 81, 02A320 (2010).

[23] B. S. Lee, S. Choi, J. H. Yoon, J. Y. Park, and M. S. Won, Manufacturing of a superconducting magnet system for $28 \mathrm{GHz}$ electron cyclotron resonance ion source at KBSI, Rev. Sci. Instrum. 83, 02 A347 (2012).

[24] W. L. Zhan et al., HIRFL today, Nucl. Phys. A805, 533C (2008).

[25] H. W. Zhao et al., Intense heavy ion beam production from IMP LECR3 and construction progress of a superconducting ECR ion source SECRAL, Rev. Sci. Instrum. 75, 1410 (2004).

[26] W. L. Zhan et al., Progress in HIRFL-CSR, Nucl. Phys. A834, 694C (2010).

[27] H. W. Zhao et al., Advanced superconducting electron cyclotron resonance ion source SECRAL: Design, construction, and the first test result, Rev. Sci. Instrum. 77, 03A333 (2006).

[28] H. W. Zhao et al., First results of SECRAL at $18 \mathrm{GHz}$ for intense beam production of highly charged ions, High Energy Phys. Nucl. Phys. 31, 8 (2007).

[29] H. W. Zhao et al., Intense beam production of highly charged heavy ions by the superconducting electron cyclotron resonance ion source SECRAL, Rev. Sci. Instrum. 79, 02A315 (2008).

[30] H. W. Zhao et al., An advanced superconducting ECR ion source SECRAL at IMP: first results and operation at 18 $\mathrm{GHz}$, in Proceedings of the 18th International Conference on Cyclotrons and Their Applications, Giardini Naxos, 2007, p. 271.

[31] H.W. Zhao et al., New development of advanced superconducting electron cyclotron resonance ion source SECRAL (invited), Rev. Sci. Instrum. 81, 02A202 (2010).

[32] L. T. Sun et al., Production of highly charged ion beams with SECRAL, Rev. Sci. Instrum. 81, 02 A318 (2010).

[33] H. W. Zhao et al., Performance and operation of advanced superconducting electron cyclotron resonance ion source SECRAL at $24 \mathrm{GHz}$, Rev. Sci. Instrum. 83, 02A320 (2012).

[34] L. T. Sun et al., Progress of superconducting electron cyclotron resonance ion sources at Institute of Modern Physics (IMP), Rev. Sci. Instrum. 85, 02 A942 (2014).

[35] L. T. Sun et al., Advancement of highly charged ion beam production by superconducting ECR ion source SECRAL (invited), Rev. Sci. Instrum. 87, 02 A707 (2016).

[36] Y.H. Zhang et al., Mass Measurements of the NeutronDeficient ${ }^{41} \mathrm{Ti},{ }^{45} \mathrm{Cr},{ }^{49} \mathrm{Fe}$, and ${ }^{53} \mathrm{Ni}$ Nuclides: First Test of the Isobaric Multiplet Mass Equation in $f p$-Shell Nuclei, Phys. Rev. Lett. 109, 102501 (2012).
[37] A. Girard, C. Pernot, G. Melin, and C. Lecot, Modeling of electron-cyclotron-resonance-heated plasmas, Phys. Rev. E 62, 1182 (2000).

[38] D. Hitz, G. Melin, and A. Girard, Fundamental aspects of electron cyclotron resonance ion sources: From classical to large superconducting devices (invited), Rev. Sci. Instrum. 71, 839 (2000).

[39] A. G. Drentje, Techniques and mechanisms applied in electron cyclotron resonance sources for highly charged ions, Rev. Sci. Instrum. 74, 2631 (2003).

[40] A. Girard, C. Lécot, and K. Serebrennikov, Numerical simulation of the plasma of an electron cyclotron resonance ion source, J. Comput. Phys. 191, 228 (2003).

[41] A. Girard, D. Hitz, and G. Melin, Electron cyclotron resonance plasmas and electron cyclotron resonance ion sources: Physics and technology (invited), Rev. Sci. Instrum. 75, 1381 (2004).

[42] F. Consoli, L. Celona, G. Ciavola, S. Gammino, F. Maimone, S. Barbarino, R. S. Catalano, and D. Mascali, Microwave field distribution and electron cyclotron resonance heating process, Rev. Sci. Instrum. 79, 02 A308 (2008).

[43] S. Gammino, D. Mascali, L. Celona, F. Maimone, and G. Ciavola, Considerations on the role of the magnetic field gradient in ECR ion sources and build-up of hot electron component, Plasma Sources Sci. Technol. 18, 045016 (2009).

[44] L. Celona, S. Gammino, F. Maimone, D. Mascali, N. Gambino, R. Miracoli, and G. Ciavola, Observations of resonant modes formation in microwave generated magnetized plasmas, Eur. Phys. J. D 61, 107 (2011).

[45] R. Rácz, S. Biri, and J. Pálinkás, ECR plasma photographs as a plasma diagnostic, Plasma Sources Sci. Technol. 20, 025002 (2011).

[46] D. Mascali, S. Gammino, L. Celona, and G. Ciavola, Towards a better comprehension of plasma formation and heating in high performances electron cyclotron resonance ion sources (invited), Rev. Sci. Instrum. 83, 02A336 (2012).

[47] B. P. Cluggish and J.-S. Kim, Modeling of wave propagation and absorption in electron cyclotron resonance ion source plasmas, Nucl. Instrum. Methods Phys. Res., Sect. A 664, 84 (2012).

[48] I. Izotov et al., Plasma instability in the afterglow of electron cyclotron resonance discharge sustained in a mirror trap, Phys. Plasmas 19, 122501 (2012).

[49] G. Torrisia, D. Mascali, G. Sorbello, L. Neri, L. Celona, G. Castro, T. Isernia, and S. Gammino, Full-wave FEM simulations of electromagnetic waves in strongly magnetized non-homogeneous plasma, J. Electromagn. Waves Appl. 28, 1085 (2014).

[50] D. Mascali1, G. Torrisi, L. Neri, G. Sorbello, G. Castro, L. Celona, and S. Gammino, 3D-full wave and kinetics numerical modelling of electron cyclotron resonance ion sources plasma: steps towards self-consistency, Eur. Phys. J. D 69, 27 (2015).

[51] V. Skalyga, I. Izotov, T. Kalvas, H. Koivisto, J. Komppula, R. Kronholm, J. Laulainen, D. Mansfeld, and O. Tarvainen, Suppression of cyclotron instability in Electron Cyclotron 
Resonance ion sources by two-frequency heating, Phys. Plasmas 22, 083509 (2015).

[52] I. Izotov, O. Tarvainen, D. Mansfeld, V. Skalyga, H. Koivisto, T. Kalvas, J. Komppula, R. Kronholm, and J. Laulainen, Microwave emission related to cyclotron instabilities in a minimum-B electron cyclotron resonance ion source plasma, Plasma Sources Sci. Technol. 24, 045017 (2015).

[53] I. Izotov, T. Kalvas, H. Koivisto, J. Komppula, R. Kronholm, J. Laulainen, D. Mansfeld, V. Skalyga, and O. Tarvainen, Cyclotron instability in the afterglow mode of minimum-B ECRIS, Rev. Sci. Instrum. 87, 02A729 (2016).

[54] O. Tarvainen, T. Kalvas, H. Koivisto, J. Komppula, R. Kronholm, J. Laulainen, I. Izotov, D. Mansfeld, and V. Skalyga, Kinetic instabilities in pulsed operation mode of a $14 \mathrm{GHz}$ electron cyclotron resonance ion source, Rev. Sci. Instrum. 87, 02A701 (2016).

[55] O. Tarvainen et al., Limitation of the ECRIS performance by kinetic plasma instabilities (invited), Rev. Sci. Instrum. 87, 02 A703 (2016).

[56] T. A. Antaya and S. Gammino, The superconducting electron cyclotron resonance $6.4 \mathrm{GHz}$ high-B mode and frequency scaling in electron cyclotron resonance ion sources, Rev. Sci. Instrum. 65, 1723 (1994).

[57] P. S. Martin and T. Nakagawa, Ion Injectors for HighIntensity Accelerators, Rev. Accel. Sci. Techol. 06, 197 (2013).

[58] R. Geller et al., The Grenoble ECRIS status 1987 and proposal for ECRIS scaling, in Proceedings of the 8th International Workshop on ECR Ion Sources, East Lansing, 1987, edited by J. Parker, NSCL Report No. MSU CP. p. 1.

[59] R. Geller, ECRIS: The Electron Cyclotron Resonance Ion Sources, Annu. Rev. Nucl. Part. Sci. 40, 15 (1990).

[60] S. Gammino, G. Ciavola, T. Antaya, and K. Harrison, Volume scaling and magnetic field scaling on SC-ECRIS at MSU-NSCL, Rev. Sci. Instrum. 67, 155 (1996).

[61] S. Gammino and G. Ciavola, The role of microwave frequency on the high charge states buildup in the ECR ion sources, Plasma Sources Sci. Technol. 5, 19 (1996).

[62] D. Hitz, A. Girard, G. Melin, S. Gammino, G. Ciavola, and L. Celona, Results and interpretation of high frequency experiments at $28 \mathrm{GHz}$ in ECR ion sources, future prospects, Rev. Sci. Instrum. 73, 509 (2002).

[63] C. M. Lyneis, Scaling laws in electron cyclotron resonance ion sources, in Proceedings of the 22nd International Workshop on ECR Ion Sources, Busan, 2016 (to be published).

[64] J. Y. Benitez et al., Recent bremsstrahlung measurements from the superconducting electron cyclotron resonance ion source VENUS, in Proceedings of the 22nd International Workshop on ECR Ion Sources, Busan, 2016 (to be published).

[65] D. Xie et al., Recent production of intense high charge ion beams with VENUS, in Proceedings of the 22nd International Workshop on ECR Ion Sources, Busan, 2016(to be published).

[66] S. Choi, Y. Kim, I. S. Hong, and D. Jeon, Superconducting magnets for the RAON electron cyclotron resonance ion source, Rev. Sci. Instrum. 85, 02 A906 (2014).
[67] H. W. Zhao et al., FECRAL a $45 \mathrm{GHz}$ fourth generation ECR ion source and its technical challenge, in Proceedings of the 22nd International Workshop on ECR Ion Sources, Busan, 2016 (to be published).

[68] C. Lyneis, D. Leitner, D. Todd, S. Virostek, T. Loew, A. Heinen, and O. Tarvainen, Measurements of bremsstrahlung production and $\mathrm{x}$-ray cryostat heating in VENUS, Rev. Sci. Instrum. 77, 03A342 (2006).

[69] M. A. Leitner et al., Progress report of the 3rd generation ECR ion source fabrication, in Proceedings of the 14th International Workshop on ECR Sources, Geneva, 1999, p. 66.

[70] C. Taylor, S. Caspi, M. Leitner, S. Lundgren, C. Lyneis, D. Wutte, S. T. Wang, and J. Y. Chen, Magnet system for an ECR ion source, IEEE Trans. Appl. Supercond. 10, 224 (2000).

[71] T. Nakagawa, Y. Higurashi, M. Kidera, T. Aihara, M. Kase, and Y. Yano, Production of multi-charged ions in the RIKEN $18 \mathrm{GHz}$ ECRIS, Nucl. Instrum. Methods Phys. Res., Sect. B 226, 392 (2004).

[72] D. Hitz, A. Girard, K. Serebrennikov, G. Melin, D. Cormier, J. M. Mathonnet, J. Chartier, L. Sun, J. P. Briand, and M. Benhachoum, Production of highly charged ion beams with the Grenoble test electron cyclotron resonance ion source (plenary), Rev. Sci. Instrum. 75, 1403 (2004).

[73] Y. Bykov, G. Denisov, A. Eremeev, V. Gorbatushkov, V. Kurkin, G. Kalynova, V. Kholoptsev, A. Luchinin, and I. Plotnikov, $28 \mathrm{GHz} 10 \mathrm{~kW}$ gyrotron system for electron cyclotron resonance ion source, Rev. Sci. Instrum. 75, 1437 (2004).

[74] Z. Q. Xie, Production of highly charged ion beams from electron cyclotron resonance ion sources (invited), Rev. Sci. Instrum. 69, 625 (1998).

[75] J. Y. Benitez, K. Y. Franzen, A. Hodgkinson, T. Loew, C. M. Lyneis, L. Phair, J. Saba, M. Strohmeier, and O. Tarvainen, Recent progress on the superconducting ion source VENUS, Rev. Sci. Instrum. 83, 02 A311 (2012).

[76] D. Leitner et al., High intensity production of high and medium charge state uranium and other heavy ion beams with VENUS, Rev. Sci. Instrum. 79, 02 C710 (2008).

[77] L. T. Sun et al., Status report of SECRAL II ion source development, in Proceedings of the 21st International Workshop on ECR Ion Sources, Nizhny Novgord, 2014, p. 94.

[78] C. Lyneis, J. Benitez, A. Hodgkinson, B. Plaum, M. Strohmeier, T. Thuillier, and D. Todd, A mode converter to generate a Gaussian-like mode for injection into the VENUS electron cyclotron resonance ion source, Rev. Sci. Instrum. 85, 02A932 (2014).

[79] J. W. Guo, L. Sun, X. J. Niu, X. Z. Zhang, W. Lu, W. H. Zhang, Y. C. Feng, and H. W. Zhao, 24 GHz microwave mode converter optimized for superconducting ECR ion source SECRAL, Rev. Sci. Instrum. 87, 02 A708 (2016).

[80] D. Leitner et al., Recent $28 \mathrm{GHz}$ results with Venus, High Energy Phys. Nucl. Phys. 31, 8 (2007).

[81] G. Melin et al., RF waves and RF coupling systems in ECR ion sources, in Proceedings of the 12th International Workshop on ECR Sources, Tokyo, 1995, p. 81. 
[82] R. Geller, Electron cyclotron resonance sources: Historical review and future prospects (invited), Rev. Sci. Instrum. 69, 1302 (1998).

[83] A. Ivanov and K. Wiesemann, Ion confinement in electron cyclotron resonance ion sources (ECRIS): importance of nonlinear plasma-wave interaction, IEEE Trans. Plasma Sci. 33, 1743 (2005).

[84] S. Gammino, L. Celona, and D. Mascali, Perspectives of Electron Cyclotron Resonance Ion Sources Beyond the Scaling Laws, IEEE Trans. Nucl. Sci. 63, 1051 (2016).

[85] D. Mascali, L. Celona, S. Gammino et al., An investigation on the formation of suprathermal electrons in a B-min ECR machine and a novel method for their damping, Plasma Sources Sci. Technol. 22, 065006 (2013).

[86] H. Koivisto et al., Maximum bremsstrahlung energy versus different heating limits, in Proceedings of the 19th ECRIS Workshop, Grenoble, France, August, WECOAK05, 2010.

[87] C. Lyneis et al., Characterization of the microwave coupling to the plasma chamber of the LBL ECR ion source, in Proceedings of the 19th ECRIS Workshop, Grenoble, France, WECOAK01, 2010.

[88] H. Arai, M. Imanaka, S.-M. Lee, Y. Higurashi, T. Nakagawa, M. Kidera, T. Kageyama, M. Kase, Y. Yano, and T. Aihara, Effect of minimum strength of mirror magnetic field $\left(B_{\min }\right)$ on production of highly charged heavy ions from RIKEN liquid-He-free super conducting electroncyclotron resonance ion source (RAMSES), Nucl. Instrum. Methods Phys. Res., Sect. A 491, 9 (2002).

[89] T. Nakagawa, Review of highly charged heavy ion production with electron cyclotron resonance ion source (invited), Rev. Sci. Instrum. 85, 02 A935 (2014).

[90] T. Nakagawa, Y. Higurashi, M. Kidera, T. Aihara, M. Kase, A. Goto, and Y. Yano, Effect of magnetic-field configuration on the beam intensity from electron cyclotron resonance ion source and RIKEN superconducting electron cyclotron resonance ion source, Rev. Sci. Instrum. 77, 03A304 (2006).

[91] D. Leitner, J. Y. Benitez, C. M. Lyneis, D. S. Todd, T. Ropponen, J. Ropponen, H. Koivisto, and S. Gammino, Measurement of the high energy component of the X-ray spectra in the VENUS electron cyclotron resonance ion source, Rev. Sci. Instrum. 79, 033302 (2008).

[92] O. Tarvainen, J. Laulainen, J. Komppula, R. Kronholm, T. Kalvas, H. Koivisto, I. Izotov, D. Mansfeld, and V. Skalyga, Limitations of electron cyclotron resonance ion source performances set by kinetic plasma instabilities, Rev. Sci. Instrum. 86, 023301 (2015).

[93] Y. Higurashi, J. Ohnishi, K. Ozeki, M. Kidera, and T. Nakagawa, Recent development of RIKEN $28 \mathrm{GHz}$ superconducting electron cyclotron resonance ion source, Rev. Sci. Instrum. 85, 02 A953 (2014).

[94] T. Nakagawa et al., Optimization of magnetic field distribution of RIKEN $28 \mathrm{GHz}$ SC-ECRIS for intense beam production, in Proceedings of the 22nd International Workshop on ECR Ion Sources, Busan, 2016(to be published).

[95] C. M. Lyneis (private communication).
[96] K. S. Golovanivsky, Physical model for very hot electron shell structures in electron cyclotron resonance plasma, Instrum. Exp. Tech. 28, 989 (1986).

[97] G. Machicoane et al., Design status of ECR ion sources and LEBT for FRIB, in Proceedings of the 20th International Workshop on ECR Ion Sources, Sydney, 2012, p. 172.

[98] Y. Yang, Y. J. Yuan, L. T. Sun, Y. C. Feng, X. Fang, Y. Cao, W. Lu, X.Z. Zhang, and H. W. Zhao, Transverse coupling property of beam from ECR ion sources, Rev. Sci. Instrum. 85, 113305 (2014).

[99] D. Leitner, C. M. Lyneis, S. R. Abbott, D. Collins, R. D. Dwinell, M. L. Galloway, M. Leitner, and D. S. Todd, Next generation ECR ion sources: First results of the superconducting $28 \mathrm{GHz}$ ECRIS - VENUS, Nucl. Instrum. Methods Phys. Res., Sect. A 235, 486 (2005).

[100] Y. Higurashi et al., Emittance measurements for RIKEN $28 \mathrm{GHz}$ SC-ECRIS, in Proceedings of the 21st International Workshop on ECR Ion Sources, Nizhny Novgord, 2014, p. 10.

[101] H. W. Zhao, World-wide developments of superconducting ECR ion sources, in Proceedings of the 1st International Particle Accelerator Conference (IPAC10), Kyoto, 2010, p. 31.

[102] H. Koivisto, Electron cyclotron resonance ion sources for highly charged ion beams, AIP Conf. Proc. 1099, 25 (2009)

[103] L. T. Sun et al., High intensity operation for heavy ion cyclotron of highly charged ECR ion sources, in Proceedings of the 20th International Conference on Cyclotrons and Their Applications, Vancouver, 2013, p. 125 .

[104] T. Thuillier, Electron cyclotron resonance source development, in Proceedings of the 20th International Conference on Cyclotrons and Their Applications, Vancouver, 2013, p. 130.

[105] T. Nakagawa, Intense highly charged heavy ion beam production, in Proceedings of the 3rd International Particle Accelerator Conference (IPAC13), Shanghai, 2013 , p. 31.

[106] O. Tarvainen et al., Beam current oscillations driven by cyclotron instabilities in a minimum-B electron cyclotron resonance ion source plasma, Plasma Sources Sci. Technol. 23, 025020 (2014).

[107] A. Kitagawa et al., Two-frequency heating technique for stable ECR plasma, in Proceedings of the 20th International Workshop on ECR Ion Sources, Sydney, 2012, p. 96.

[108] R. C. Vondrasek, R. Scott, and R. C. Pardo, ECRIS operation with multiple frequencies, Rev. Sci. Instrum. 77, 03A337 (2006).

[109] L. T. Sun et al., SECRAL II ion source development and the first commissioning at $28 \mathrm{GHz}$, in Proceedings of the 22nd International Workshop on ECR Ion Sources, Busan, 2016 (to be published).

[110] C. Lyneis, P. Ferracin, S. Caspi, A. Hodgkinson, and G. L. Sabbi, Concept for a fourth generation electron cyclotron resonance ion source, Rev. Sci. Instrum. 83, 02A301 (2012). 